\title{
A New Velocity Field from a Dense GPS Array in the Southernmost Longitudinal Valley, Southeastern Taiwan
}

\author{
Horng-Yue Chen ${ }^{1, *}$, Jian-Cheng Lee ${ }^{1}$, Hsin Tung ${ }^{1}$, Shui-Beih $\mathrm{Yu}^{1}$, Ya-Ju Hsu ${ }^{1}$, and Hungkyu Lee ${ }^{2}$ \\ ${ }^{1}$ Institute of Earth Sciences, Academia Sinica, Taipei, Taiwan \\ ${ }^{2}$ Department of Civil Engineering, Changwon National University, Gyeongnam, Korea
}

Received 8 March 2013, accepted 18 June 2013

\begin{abstract}
In the southernmost Longitudinal Valley (LV), Taiwan, we analyzed a dense GPS array composed of 10 continuous stations and 86 campaign-mode stations. By removing the effects of the four major earthquakes (one regional and three local) occurred during the 1992 - 2010 observation period, we derived a new horizontal velocity field in this area, which then allows better locating the surface traces of the major active faults, including the Longitudinal Valley Fault (LVF) system and the Central Range Fault, and characterizing the slip behaviors along the faults. Note that LVF reveals two sub-parallel strands in the study area: the Luyeh Fault to the west and the Lichi Fault to the east. Based on the results of strain analyses, including dilatation and shear strain, and projected vectors of station velocities across the major faults, we came to the following geological interpretations. During the inter-seismic periods, the surface deformation of the southernmost LV is mainly accommodated by the faulting on the two branches of the LVF; there is very little surface deformation on the Central Range Fault. The Luyeh River appears to act as a boundary to divide the LVF to behave differently to its northern and southern sides. The Lichi Fault reveals a change of slip kinematics from an oblique shearing/thrusting in the north to a nearly pure shearing with minor extension to the south. Regarding the slip behavior of the Luyeh Fault, it exhibits a creeping behavior in the north and a partially near-surface-locked faulting behavior in the south. We interpret that the two strands of the LVF merge together in the northern Taitung alluvial plain and turns to E-W trend toward the offshore area.
\end{abstract}

Key words: GPS, Longitudinal Valley, Near-fault deformation, Taiwan

Citation: Chen, H.Y., J. C. Lee, H. Tung, S. B. Yu, Y. J. Hsu, and H. Lee, 2013: A new velocity field from a dense GPS array in the southernmost Longitudinal Valley, southeastern Taiwan. Terr. Atmos. Ocean. Sci., 24, 837-862, doi: 10.3319/TAO.2013.06.18.01(T)

\section{INTRODUCTION}

The island of Taiwan is situated in the convergent boundary between Eurasia and the Philippine Sea plate. The active plate convergence results in frequent earthquakes and significant crustal deformation. To the northeast offshore of Taiwan, the Philippine Sea plate subducts under the continental margin of the Eurasian plate. On the other hand, to the southwest of Taiwan, the South China Sea of the Eurasian plate subducts eastwards to the Philippine Sea plate in southern Taiwan. Under this rather complex plate configuration of two opposing subduction zones, the Longitudinal Valley in eastern Taiwan is an on-land suture zone between the two plates and is located geologically between the Central Range of metamorphic rock of the Chinese continental margin in the

\footnotetext{
* Corresponding author

E-mail: chenhy@earth.sinica.edu.tw
}

west and the Coastal Range of volcanic arc of the Philippine Sea plate in the east. The Longitudinal Valley Fault (LVF in Fig. 1a), which represents the major fault system in this 180-km-long narrow valley, consists of several active segments and its surface trace follows generally the eastern side of the Longitudinal Valley, featuring both left-lateral strikeslip and high-angle thrust components (Yu et al. 1990; Lee and Angelier 1993; Angelier et al. 1997; Shyu et al. 2005).

This study is focused on the southernmost Longitudinal Valley area (Fig. 1b). In the southernmost part of the Longitudinal Valley, the Peinanshan massif (PS in Fig. 1b), which stands in the middle of the valley of about 6-km-long, 3-km-wide, 2-3-hundreds-meter-high, is bounded by three faults: two branches of the LVF on the both side of the massif and one steeply west-dipping fault beneath the west side of the massif (i.e., the Central Range Fault), showing a rather 


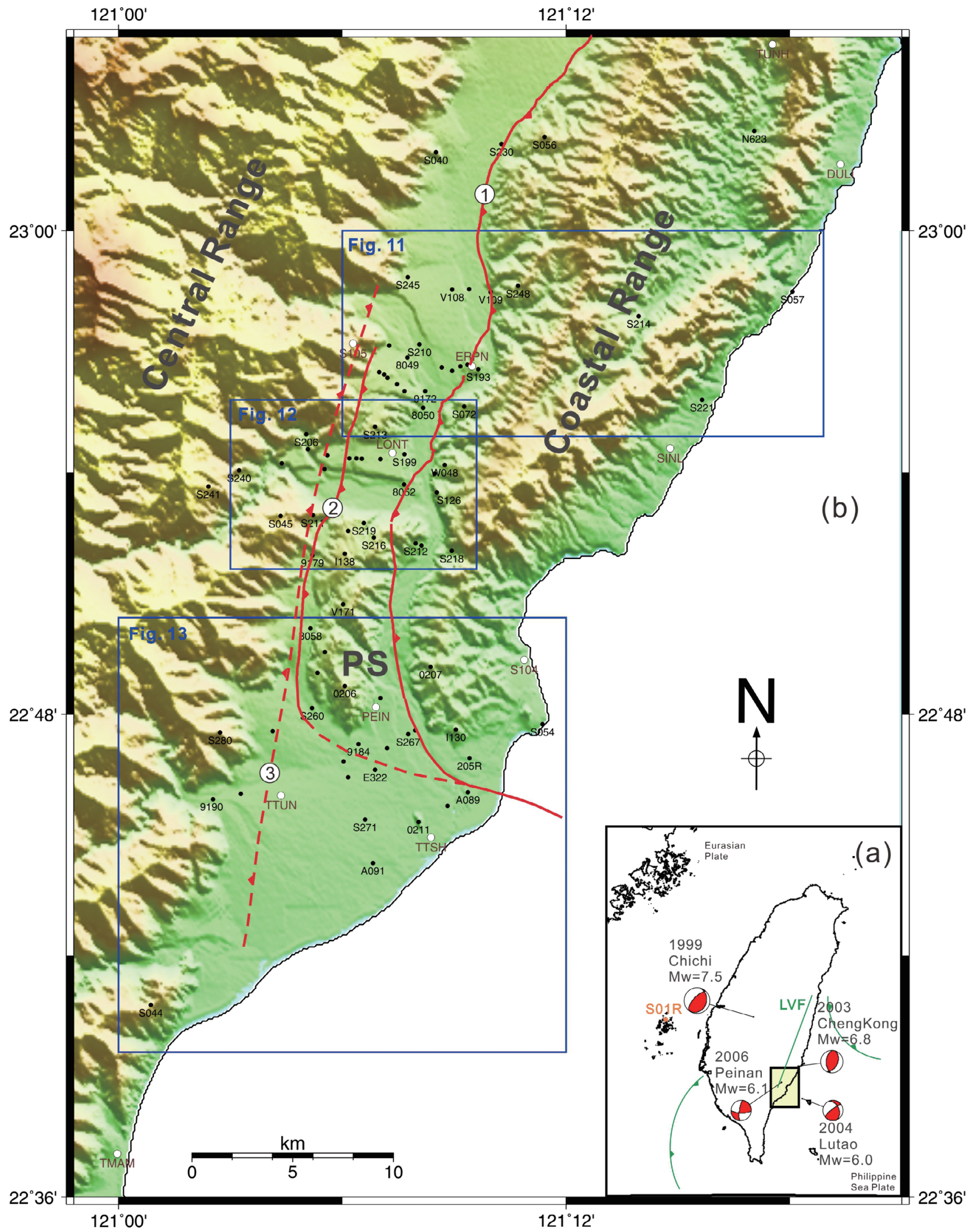

Fig. 1. The dense GPS array in the southernmost Longitudinal Valley of southeastern Taiwan. The inset in the lower right shows the general tectonic framework of Taiwan with four major earthquakes, which are considered to influence the study area. The GPS station S01R in a small island of the Taiwan Strait serves as the reference station in GPS data processing. The solid circles represent the CMS stations, and the open circles show the CORS. Major active faults are marked with heavy red lines or curves: 1: Lichi Fault, 2: Luyeh Fault and 3: Central Range Fault. 
complex fault system in this area. For the two branches of the LVF, both east-dipping reverse faults, the Lichi Fault cuts through the eastern side of the Peinanshan massif and is an oblique reverse fault with significant left-lateral strikeslip component (Lee et al. 1998; Yu and Kuo 2001). The Luyeh Fault, which has been treated as a nearly pure thrust fault, runs along the west side of the Peinanshan massif (Lee et al. 1998; Hu et al. 2001). On the one hand, the Luyeh Fault seems to terminate gradually in the north (Shyu et al. 2002) and was speculated to bend dramatically to E-W trending before joining the Lichi Fault in the south (Chen et al.2012). This is one of the main points we intend to address in this paper. As for the west-dipping Central Range Fault, which has recently been ruptured during the 2006 M 6.1 Peinan earthquake, it is still under debate regarding the geological context whether it is a major geological boundary between the Central Range and the Coastal Range (Shyu et al. 2002; Chen et al. 2009). Furthermore, the inter-seismic surface deformation and slip behaviors of the fault remain unclear.

Geologically, to the west of the valley, the Central Range belongs to the continental margin of the Eurasian crust rising to a height of about $3000 \mathrm{~m}$ at a short distance of less than $10 \mathrm{~km}$. The rock formations of the Central Range consist of the Tananao metamorphic complex and the slate belt. To the east of the valley, the Coastal Range is part of the Luzon arc sitting on the Philippine Sea plate with elevations ranging from several hundred to $2000 \mathrm{~m}$. Strata in the Coastal Range are divided into five geologic units: igneous rocks of the $\mathrm{Tu}$ luanshan formation (i.e., arc basement), the overlying deep sea turbidite of the Fensuliao formation and the Paliwan formation, and the Lichi melange, composed of mainly clay matrix with a mixture of various kinds of exotic blocks. Within the valley, the Peinanshan massif in the vicinity of the Peinan and Kaotai tableland, is a thick layer of late Quaternary gravels intercalation with sandstone and occasionally mudstone. The gravel is composed of slate, schist, crystalline metamorphic mafic igneous, metamorphic sandstone, limestone and sandstone, which were transported by rivers flowing mainly from the Central Range of metamorphic rocks.

The Longitudinal Valley itself is composed of alluvium, which is mainly piled up by the sediments brought from both the Central Range and the Coastal Range. The river systems, which carry the sediments into the valley, often produce alluvial fans at the foot of the two ranges in the valley. In the study area of the southernmost Longitudinal Valley, along the Luyeh River there exist several (5 - 7) levels of Holocene river terraces (Shyu et al. 2002). The uppermost two terraces are the laterite gravels layers, which are widely distributed in the highlands of the Peinan tableland and the Kaotai tableland with a ${ }^{14} \mathrm{C}$ age of about $3500 \mathrm{yr}$ (Shyu et al. 2008). The heights of these Holocene young terraces are up to $70 \mathrm{~m}$ with respect to the present Luyeh riverbed, indicating a rigorous tectonic and erosion activity (i.e., a combining rate of $2 \mathrm{~cm} \mathrm{yr}^{-1}$ for terrace uplift and river incision) in the study area.

According to previous geodetic measurements, including trilateration (Yu et al. 1992) and GPS results (Yu et al. 1997; Yu and Kuo 2001), the horizontal shortening rate of the southernmost Longitudinal Valley area absorbs about $30 \mathrm{~mm} \mathrm{yr}^{-1}$, which is about $36 \%$ of the total shortening $\left(82 \mathrm{~mm} \mathrm{yr}^{-1}\right)$ across the whole Taiwan mountain belt. The crustal deformation was mainly accommodated by faulting of the two branches of the LVF, the Luyeh Fault and the Lichi Fault. However, the Central Range Fault also plays a role, although to a lesser degree, on the active tectonics in the southernmost Longitudinal Valley area. Indeed the 2006 M 6.1 Peinan earthquake ruptured this fault although the coseismic fault slip did not reach the surface (Wu et al. 2006; Chen et al. 2009; Mozziconacci et al. 2013). Regarding the vertical deformation, our recent analysis of vertical velocity field combining leveling and GPS data (Chen et al. 2012) showed that the faulting of the two branches of the LVF dominated the surface inter-seismic vertical deformation in the southernmost Longitudinal Valley: (a) the hanging wall of the Lichi Fault (i.e., the Coastal Range) is uplifting at a rapid rate, (b) the hanging wall of the Luyeh Fault (i.e., the Kaotai and Peinanshan tablelands) reveals a variation of moderate uplift or subsidence, (c) the footwall of the LVF (i.e., the flat area of the valley) shows significant subsidence, and (d) the Central Range exhibits a slight to moderate subsidence. However, this vertical velocity cannot provide the information on the horizontal especially the strike-slip components of the aforementioned three faults. In fact, based on the earlier analysis of the 1985 - 1988 trilateration data, Lee et al. (1998) argued that the Lichi Fault behaved as a nearly pure strike-slip fault and the Luyeh Fault acted as a near pure reverse fault. However, later GPS data of 1991 - 1999 (Yu and Kuo 2001) suggested somehow otherwise: the Lichi Fault indicated an oblique reverse faulting with minor left-lateral component and not pure strike-slip faulting. This is one of the issues that this study would discuss. Another unsolved problem in the study area was the location of the surface traces of the southern end of the Luyeh Fault and the Lichi Fault in the Taitung alluvial plain. Where runs the Luyeh Fault when it continues toward the south? Does it joins the Lichi Fault, and how? How the Lichi Fault (and the LVF system) connects to the offshore fault system, which marks the western margin of the Luzon arc?

In an attempt to answer the above questions and to better characterize the crustal strain rate and the fault activities in southernmost Longitudinal Valley area, we analyzed the observation results from a dense GPS array composed of 10 CORS (Continuously Operating Reference Station) operated by different agencies since 1994 and 86 CMS (Campaign-Mode Station) surveyed mostly annually since 1992 (Fig. 1). Based on the 1992 - 2010 GPS data collected by this dense GPS array, we derived a new horizontal velocity field, presumably reflecting the inter-seismic velocity, 
in the southernmost Longitudinal Valley area. We also incorporated recently published leveling results to discuss the detailed location of the surface traces of the three aforementioned major active faults, their surface slip behaviors, and possible tectonic implications.

\section{DATA ACQUISITION AND PROCESSING}

During 1992 - 2000, only 18 CMS were surveyed annually and 3 CORS were in operation in southeastern Taiwan (Yu and Kuo 2001). Additional 68 CMS and 7 CORS have been deployed to form a dense GPS array in the studied area since 2001 (Table 1). For the CMS survey, 8 to 12 stations were occupied simultaneously with dual-frequency geodetic GPS receivers and an observation session was 7 - 14 hours. The sampling rate was 15 seconds and the cutoff angle was $10^{\circ}$ in elevation. The raw data were transferred to RINEX (Receiver INdependent EXchange) format for post-processing. During the field observations, effort was made to remove environmental obstructions, such as trees or grass, to reduce the effect from multipath. All equipment was checked and adjusted, such as leveling and centering biases of tribranches to reduce the centering errors, before each field campaign. For the continuously recording GPS stations (CORS), the receiver setting was similar to that for the campaign stations, except the data logging was in two types either in 30 seconds or in $1 \mathrm{~Hz}$ (Yu et al. 2001). All GPS data were processed into a daily solution following the standard procedures of the Bernese software (Dach et al. 2007). The daily solutions were incorporated into a session solution for campaigned surveys, using also the Bernese software. The station, S01R, at Penghu located at the stable Chinese continental margin (Fig. 1a) was selected to define the "minimum constrained conditions" to its International Terrestrial Reference Frame 2005 (ITRF05) value.

The detailed procedures of data processing procedure for determinations of daily solutions (CORS) and session solutions (CMS) are briefly described below.

(1) Employ the International GPS service (IGS) final orbit to reduce the effects of the orbit errors.

(2) Utilize the antenna calibration tables provided by the Astronomical Institute, University of Bern, (AIUB), National Geodetic Survey (NGS) and National Oceanic and Atmospheric Administration, U.S. Department of Commerce to reduce the effects of the phase center biases.

(3) Form the double-differenced ionosphere-free linear combination of carrier phase observations to mitigate the first order ionospheric bias.

(4) Estimate the difference between the actual zenith delay based upon a standard atmosphere model (Saastamoinen 1973) to determine the residual tropospheric zenith delay, then conduct estimates of every 2 hours per station simultaneously with the station coordinates by least square adjustments.

(5) Constrain the daily solution to reference 'fixed' station, the Paisha station, at Penghu (S01R), which has a precise ITRF05 coordinate and is located in the stable Chinese continental margin.

(6) Combine the daily solutions into a session solution for the campaigned measurements.

(7) Output the daily solution or session solution in the format of SINEX (Software Independent Exchange).

\section{ESTIMATION OF THE INTER-SEISMIC VELOC- ITY}

\subsection{CORS Position Time Series}

During the 1992 - 2010 observation period, four major earthquakes with magnitude larger than 6 occurred in the vicinity of the southernmost Longitudinal Valley: the 1999 $\mathrm{M}_{\mathrm{w}}$ 7.6 Chi-Chi earthquake, the $2003 \mathrm{M}_{\mathrm{L}}$ 6.5 Chengkung $2004 \mathrm{M}_{\mathrm{L}} 6.0$ Lutao and $2006 \mathrm{M}_{\mathrm{L}} 6.1$ Peinan earthquakes. All caused significant co- and post-seismic displacements (Chen et al. 2006, 2009; Lee et al. 2006; Mozziconacci et al. 2013).

Table 1. ITRF2005 velocities of CORS in the southernmost Longitudinal Valley area, southeastern Taiwan.

\begin{tabular}{lcccccc}
\hline Station & Lat $\left(^{\circ}\right)$ & Lon $\left(^{\circ}\right)$ & $\mathbf{N}\left(\mathbf{m m ~ y r}^{-1}\right)$ & $\mathbf{E}\left(\mathbf{m m} \mathbf{y r}^{-1}\right)$ & Data period $(\mathbf{y r})$ & Data num. \\
\hline DULI & 23.0257 & 121.3306 & $33.7 \pm 0.3$ & $-19.8 \pm 0.5$ & $2006.4-2010.8$ & 989 \\
ERPN & 22.9422 & 121.1661 & $30.1 \pm 0.1$ & $-27.9 \pm 0.1$ & $2002.0-2010.6$ & 2907 \\
LONT & 22.9063 & 121.1306 & $-0.2 \pm 0.1$ & $-8.4 \pm 0.1$ & $2003.0-2010.6$ & 2450 \\
PEIN & 22.8011 & 121.1231 & $-21.0 \pm 0.2$ & $-23.4 \pm 0.1$ & $2006.0-2010.6$ & 1106 \\
SINL & 22.9083 & 121.2546 & $27.8 \pm 0.1$ & $-21.9 \pm 0.1$ & $2006.0-2010.6$ & 1527 \\
TMAM & 22.6161 & 121.0075 & $-8.5 \pm 0.1$ & $-10.7 \pm 0.1$ & $1999.7-2010.6$ & 2999 \\
TTSH & 22.7471 & 121.1476 & $-3.2 \pm 0.2$ & $-18.3 \pm 0.4$ & $2009.0-2012.2$ & 939 \\
TTUN & 22.7646 & 121.0807 & $-20.4 \pm 0.2$ & $-17.0 \pm 0.1$ & $2003.0-2010.6$ & 2329 \\
S104 & 22.8208 & 121.1894 & $26.1 \pm 0.1$ & $-24.3 \pm 0.1$ & $1994.1-2010.6$ & 5218 \\
S105 & 22.9517 & 121.1129 & $-1.9 \pm 0.1$ & $-3.4 \pm 0.1$ & $1994.0-2010.6$ & 4858 \\
\hline
\end{tabular}


It is thus necessary to remove the effects of these four earthquakes in order to estimate the inter-seismic velocity. The model proposed by Nikolaidis (2002) was applied to analyze the CORS position time series data sets as the following.

$$
\begin{aligned}
y\left(t_{i}\right)= & a+b t_{i}+c \sin \left(2 \pi t_{i}\right)+d \cos \left(2 \pi t_{i}\right)+e \sin \left(4 \pi t_{i}\right) \\
& +f \cos \left(4 \pi t_{i}\right)+\sum_{j=1}^{n_{g}} g_{j} H\left(t_{i}-T_{g j}\right)+\sum_{j=1}^{n_{h}} h_{j} H\left(t_{i}-T_{h j}\right)_{t_{i}} \\
& +\sum_{j=1}^{n^{\prime \prime} k} k_{j} \exp \left[-\left(t_{i}-T_{k j}\right) / \tau_{j}\right] H\left(t_{i}-T\right)+\nu_{i}
\end{aligned}
$$

where

$a$ and $b$ represent the intercept and the linear variation of the inter-seismic velocity, respectively;

$c, d, e$ and $f$ denote annual and semi-annual periodic motions;

$g$ presents the co-seismic displacement;

$h$ expresses the change of the linear velocity after the earthquake;

$k$ implies the exponential decay of the post-seismic displacement;

$H(t)$ is the Heaviside step function;

$\tau$ displays the relaxation time of post-seismic deformation; $v$ indicates the model residuals.

For the CORS position time series data, the annual and semi-annual periodic motions, co-seismic and post-seismic displacements can be considered in Eq. (1). Figures 2 - 4 show examples of the determination of inter-seismic horizontal velocity from CORS time series data. We can find that the inter-seismic horizontal components (both East and North directions) can be calibrated into a linear trend after removing the seasonal and co- and post-seismic effects from $\mathrm{Eq}$ (1). The data period, number of data points, and the estimated ITRF2005 horizontal velocities with their standard deviations of the 10 CORS are listed in Table 1. And the yielded values of the parameters (constants) in Eq (1), that is $a, b, c, d, e, f, g$, and $k$, are shown in Table 2 .

\subsection{Campaign-Surveyed Data}

For the CMS data that measured only one or two times a year, it is not possible to be applied to the calculation of Eq. (1). The station velocity is assumed to be a linear variation, except temporary perturbations induced by the nearby large to moderate earthquakes (i.e., the 1999 Chi-Chi, the 2003 Chengkung, the 2004 Lutao and the 2006 Peinan earthquakes). By removing the co- and post-seismic effects, which presumably did not cause significant change on the secular long-term inter-seismic velocity, we obtain interseismic station velocity,

$y\left(t_{i}\right)=a+b t_{i}$ where $a$ and $b$ represent intercept and the linear variation of the inter-seismic velocity, respectively. The most important, challenging part of the CMS data processing is to remove the influences of the aforementioned four nearby moderate earthquakes, which included both the co-seismic and post-seismic effects. Instead of estimating the exact co- and post-seismic displacements, we aimed at removing their effects on some particular surveys. In practice, we examined carefully the CMS data station by station. We calibrated the surveys conducted immediately after each of the four earthquakes in cases that the data revealing the co-seismic effect, by fitting the data into pre-earthquake linear trend. We also calibrated the surveys apparently affected by post-seismic effects, as they did not fit the linear trend of the velocity during a short period following the main shock.

Here we present a few examples in different geological terrains, including the station S044 in eastern Central Range (Fig. 5), 0206 in the Longitudinal Valley (Fig. 6) and 0207, S054 in the Coastal Range (Figs. 7 and 8), to illustrate how the perturbations were removing from above four large or moderate earthquakes to obtain the inter-seismic velocity. For CMS data, we basically occupied at least once per year, hence there are usually more than 2 surveys of observations in-between the four moderate earthquakes mentioned above, which help to calibrate the linear trend. The whole data sets can be divided into four or five segments for each station (Figs. 5 - 8). Then the offsets can be estimated by a linear fit at the time of earthquakes, after removing the offsets the velocities can be acquired for each station of the whole data set. The data period, number of data points, and the estimated ITRF2005 horizontal velocities with their standard deviations of the 86 CMS are listed in Table 3.

\subsection{GPS Horizontal Velocity Field}

After removing the effects of the aforementioned four earthquakes, the estimated inter-seismic velocities in the ITRF2005 reference frame (Altimimi et al. 2007) for the 10 CORS and $84 \mathrm{CMS}$ in the southernmost Longitudinal Valley area are shown in Fig. 9 and Table 1. We can find different patterns of GPS motions across the major active faults, especially along the two branches of the LVF. In general, the GPS velocities in three major geological terrains show different features: (1) in the Coastal Range, the hanging wall of the LVF, the station velocities are about $30-50 \mathrm{~mm} \mathrm{yr}^{-1}$ in the NW directions with azimuths of $308^{\circ}-322^{\circ}$; (2) by contrast in the Central Range, the station velocities are of much slow rates of $2-14 \mathrm{~mm} \mathrm{yr}^{-1}$ in opposing directions with a rather large variation from NE to SSE with azimuths of $60^{\circ}-170^{\circ}$; (3) finally within the Longitudinal Valley, we find a very slow rate of velocities $\left(<10 \mathrm{~mm} \mathrm{yr}^{-1}\right)$ in the north, whereas in the southern Peinan tableland and Taitung alluvial plain, the station velocities are $14-31 \mathrm{~mm} \mathrm{yr}^{-1}$ in the SW to WSW directions of $203^{\circ}-247^{\circ}$. 
(a)

S105
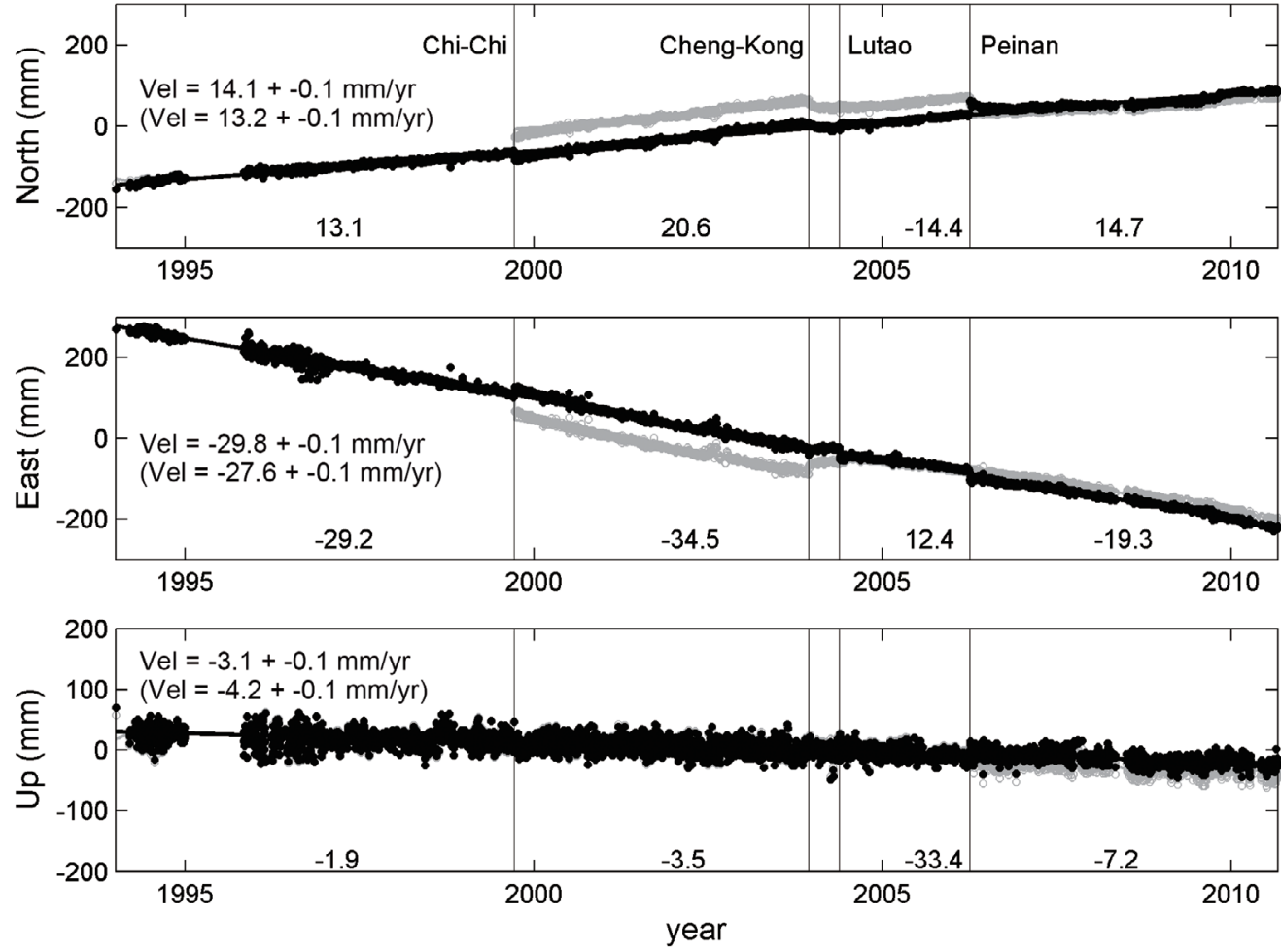

(b)

TMAM
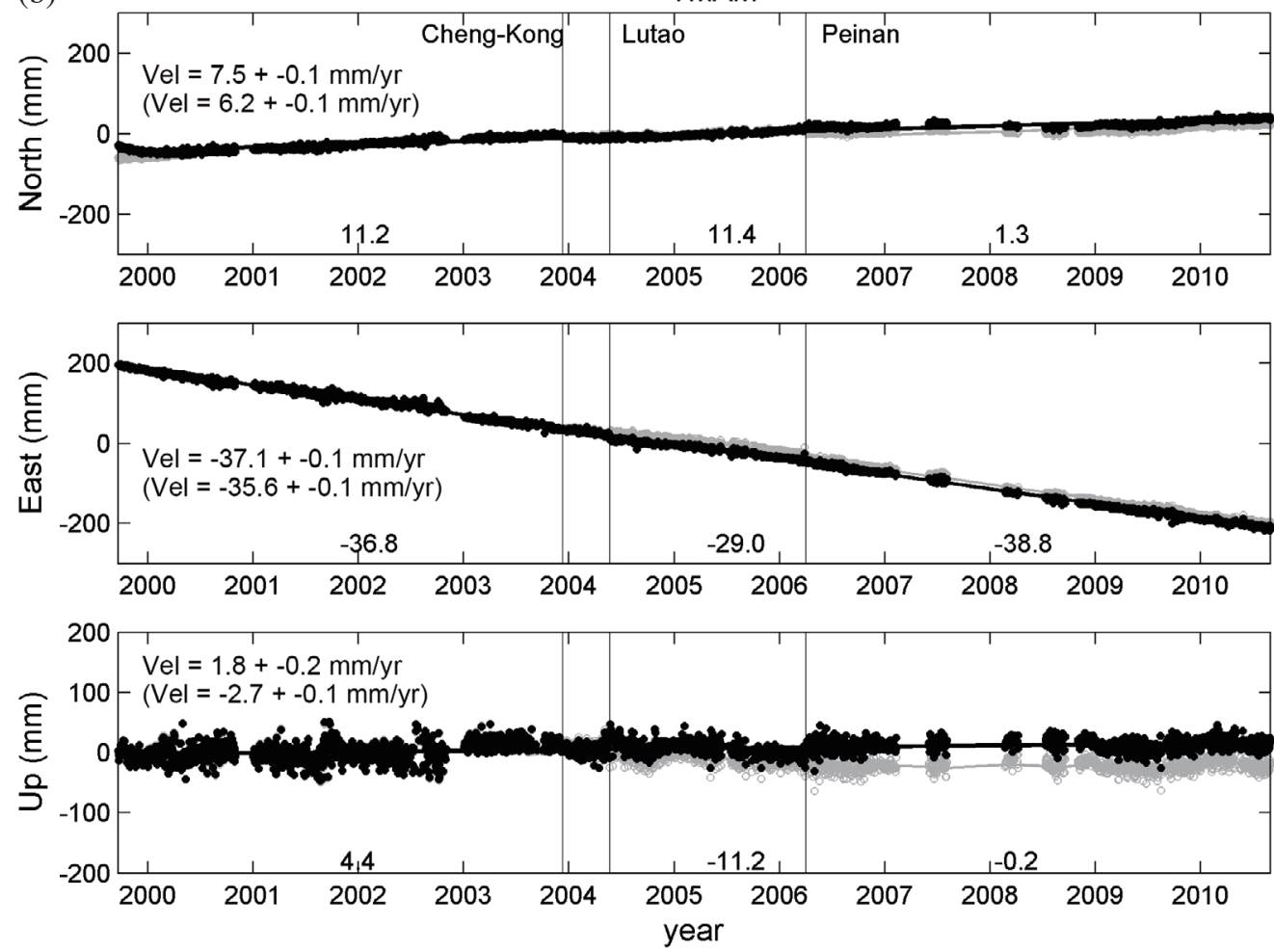

Fig. 2. Examples of time series and determination of GPS velocity for CORS stations in the Central Range: (a) S105 and (b) TMAM. The scatters are subtracted to the mean value. Open circles in grey show the raw data and solid dots in black represent the calibrated results. The number with the uncertainty value (i.e., $1 \sigma$ of standard deviation) on the right hand corner expresses the station velocity fit by a linear trend. The number in the parenthesis indicates the long-term velocity without calibration for earthquake effects. Note that the values for North, East and Up components are with respect to the station S01R. 
(a)
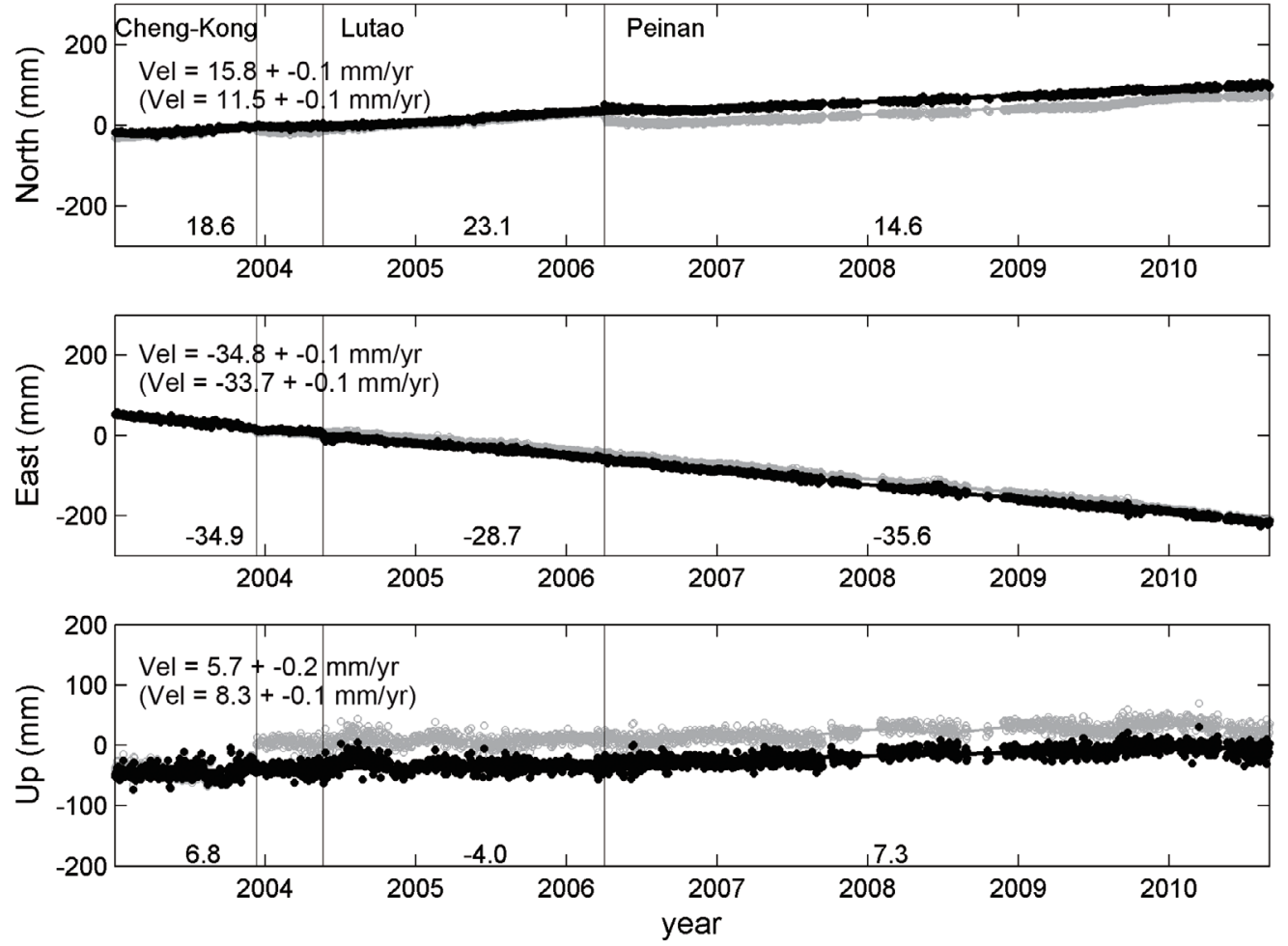

(b) TTUN
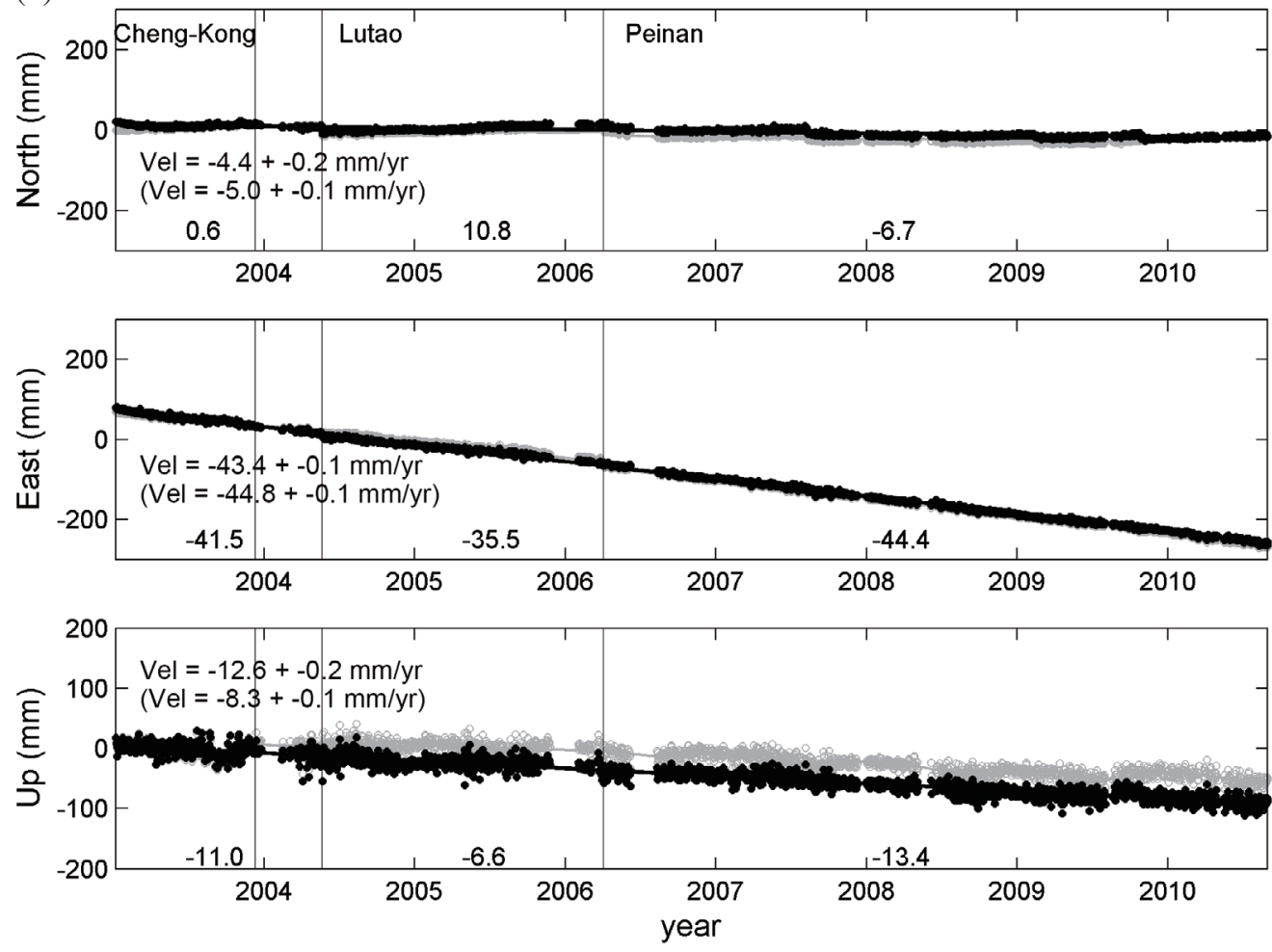

Fig. 3. Examples of time series and determination of GPS velocity for CORS stations, (a) LONT and (b) TTUN, within the Longitudinal Valley. Symbols: see detailed descriptions in Fig. 2. 
(a)
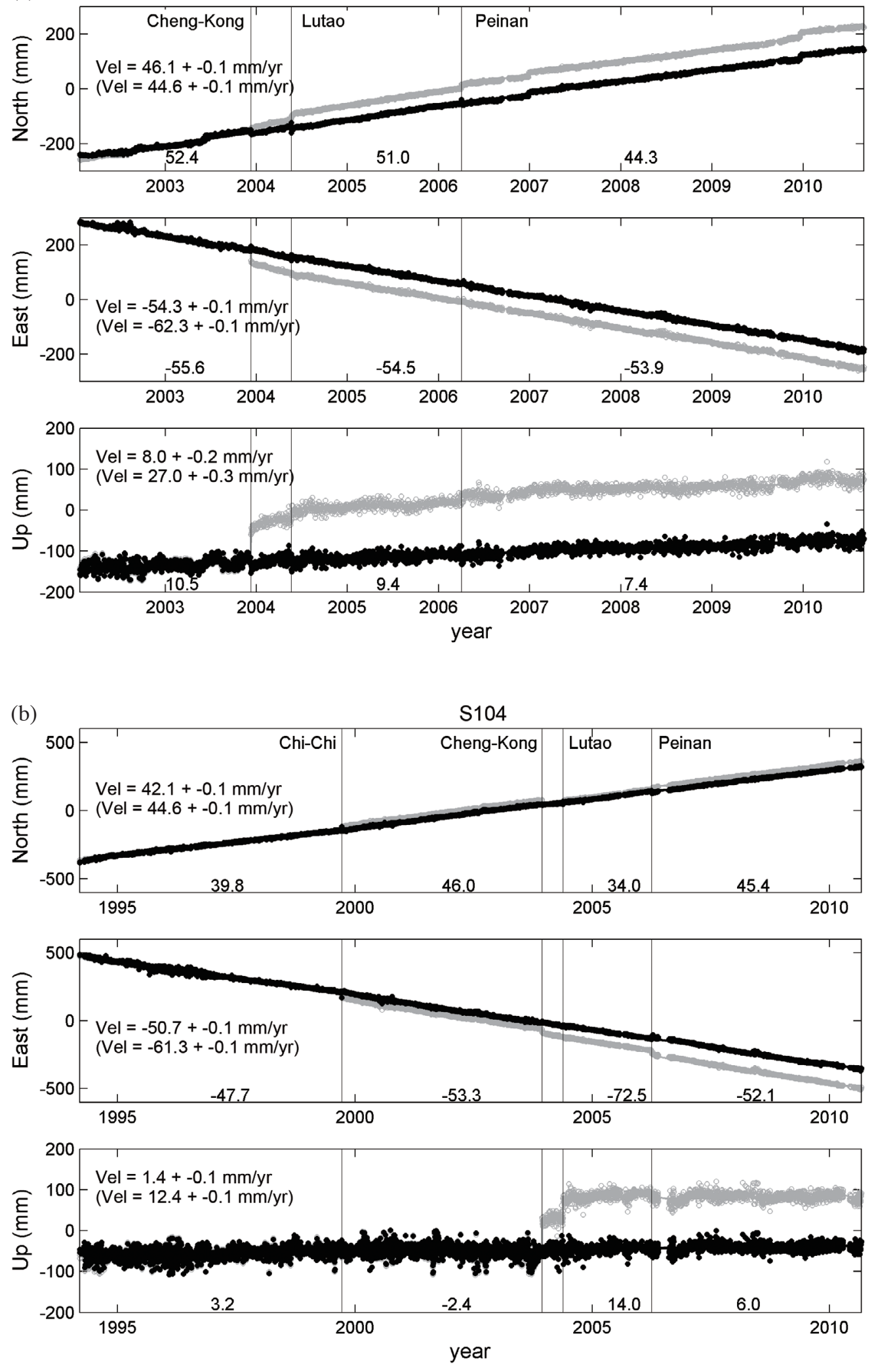

Fig. 4. Examples of time series and determination of GPS velocity for CORS stations in the Coastal Range: (a) ERPN and (b) S104. Symbols: see detailed descriptions in Fig. 2. 
Table 2. The results of the yielded values for the constants in the equation [Eq. (1)] to fit the time series of continuous GPS data.

\begin{tabular}{l|rrrrrrrrrrc}
\hline Station & a & b & c & d & e & f & g1 (1999) & g2 (2003) & g3 (2006) & g4 (2006) & k \\
\hline S104 & 101236.19 & -50.68 & -0.28 & -0.49 & -0.41 & -0.10 & -44.40 & -34.83 & -7.32 & -42.60 & 0.00 \\
S105 & 59614.10 & -29.85 & -0.06 & 0.64 & 0.10 & -0.26 & -60.70 & 26.96 & 29.75 & 22.53 & 0.00 \\
ERPN & 108953.96 & -54.34 & -1.37 & 0.36 & 0.35 & 0.17 & N/A & -53.24 & -10.12 & -0.99 & 0.00 \\
LONT & 69829.19 & -34.84 & 0.26 & 0.76 & 0.53 & -0.07 & N/A & -4.01 & 16.69 & 1.17 & 0.00 \\
TMAM & 74310.90 & -37.06 & -1.06 & 0.19 & -0.02 & -0.05 & N/A & 3.27 & 13.07 & -5.04 & 0.00 \\
TTUN & 87082.70 & 43.44 & -0.35 & 0.40 & 0.63 & -0.54 & N/A & 2.40 & 6.60 & -12.81 & -0.24 \\
PEIN & 100041.71 & -49.81 & -0.41 & 0.00 & -0.48 & -0.06 & N/A & N/A & N/A & -36.13 & 4.59 \\
SINL & 97097.98 & -48.34 & -0.48 & -0.22 & 0.13 & 0.30 & N/A & N/A & N/A & -4.70 & -1.43 \\
DULI & 92834.99 & -46.21 & -0.66 & -0.41 & -2.34 & 2.37 & N/A & N/A & N/A & N/A & -6.61 \\
TTSH & 89844.20 & -44.69 & 1.47 & 3.28 & -0.53 & 0.21 & N/A & N/A & N/A & N/A & 0.03 \\
\hline
\end{tabular}

Note: East component.

\begin{tabular}{l|ccccccccccc}
\hline Station & $\mathbf{a}$ & $\mathbf{b}$ & $\mathbf{c}$ & $\mathbf{d}$ & $\mathbf{c}$ & $\mathbf{f}$ & $\mathbf{g 1}(\mathbf{1 9 9 9})$ & $\mathbf{g 2}(\mathbf{2 0 0 3})$ & $\mathbf{g 3}(\mathbf{2 0 0 6})$ & $\mathbf{g 4}(\mathbf{2 0 0 6})$ & $\mathbf{k}$ \\
\hline S104 & -84063.42 & 42.09 & -0.15 & 1.35 & -0.55 & -0.16 & 29.56 & -29.72 & 14.63 & 20.16 & 0.00 \\
S105 & -28202.68 & 14.12 & 0.28 & -0.42 & -0.95 & 0.00 & 57.12 & -7.56 & -6.98 & -50.71 & 0.00 \\
ERPN & -92521.99 & 46.14 & 0.78 & 0.48 & 0.86 & -0.49 & N/A & 23.79 & 29.30 & 18.45 & 0.01 \\
LONT & -31675.69 & 15.80 & 0.03 & 1.24 & -0.21 & -0.77 & N/A & -13.66 & 9.13 & -27.11 & -0.32 \\
TMAM & -15081.40 & 7.52 & -0.66 & -0.56 & -0.98 & -0.08 & N/A & 4.42 & -2.08 & -16.30 & 0.00 \\
TTUN & 8850.25 & -4.41 & 1.46 & -0.67 & -0.03 & -0.64 & N/A & 0.31 & -5.81 & -8.41 & -0.50 \\
PEIN & 9981.05 & -4.98 & 1.58 & -1.10 & -0.17 & -0.33 & N/A & N/A & N/A & 7.27 & 9.10 \\
SINL & -87919.35 & 43.77 & 0.80 & 1.23 & 0.19 & 0.09 & N/A & N/A & N/A & 5.06 & -3.64 \\
DULI & -96225.86 & 47.89 & 2.10 & 1.62 & -0.93 & 1.09 & N/A & N/A & N/A & N/A & -1.40 \\
TTSH & -25649.46 & 12.76 & 1.17 & 0.12 & -0.22 & 0.09 & N/A & N/A & N/A & N/A & 0.41 \\
\hline
\end{tabular}

Note: North component.
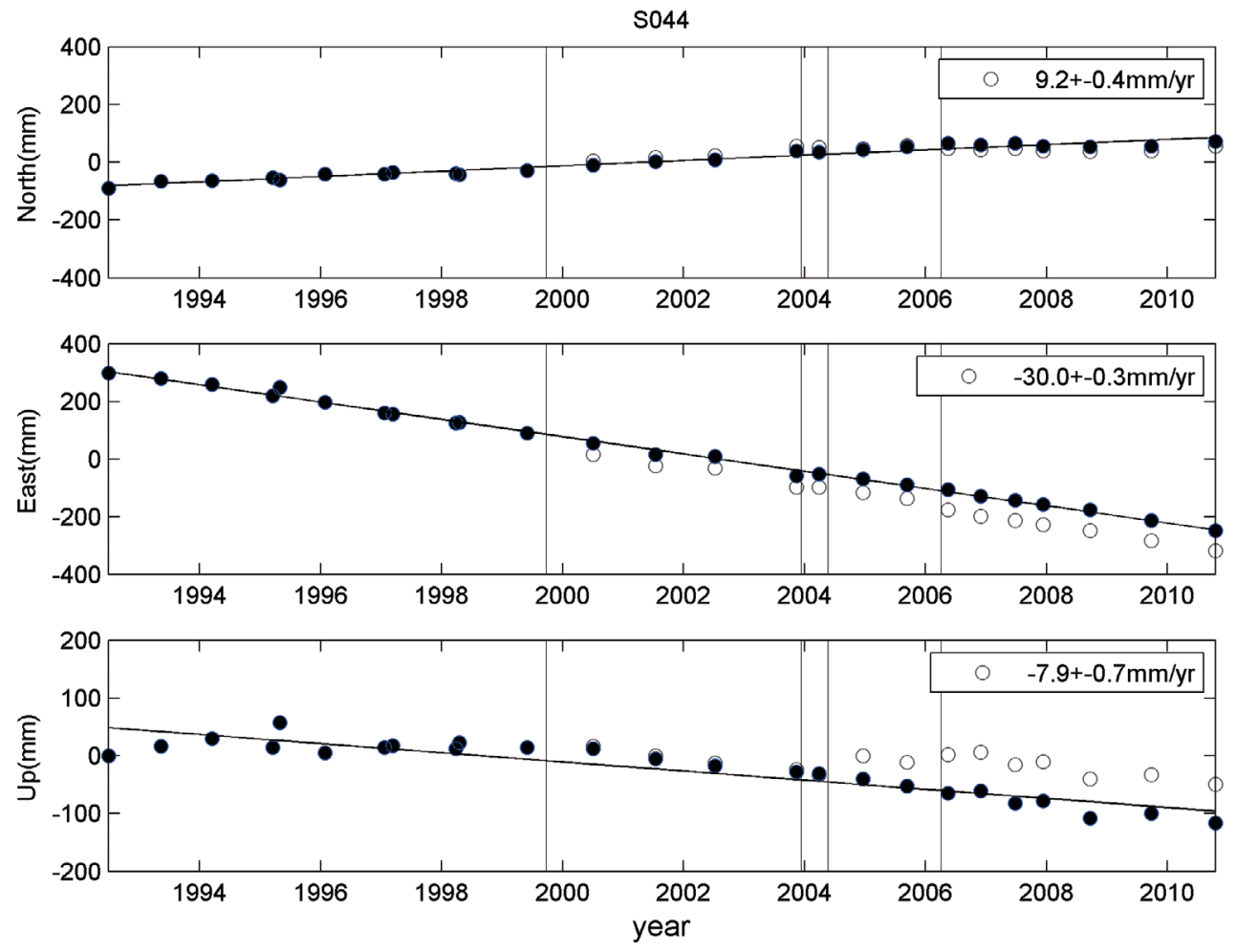

Fig. 5. Examples of campaigned GPS time series (open circles) and calibration after removing the earthquake effects (black solid circles) for station S044 in the eastern flank of the Central Range. The GPS inter-seismic velocities, which were obtained by linear fits, are expressed by the numbers with uncertainty of $1 \sigma$ standard deviation. 

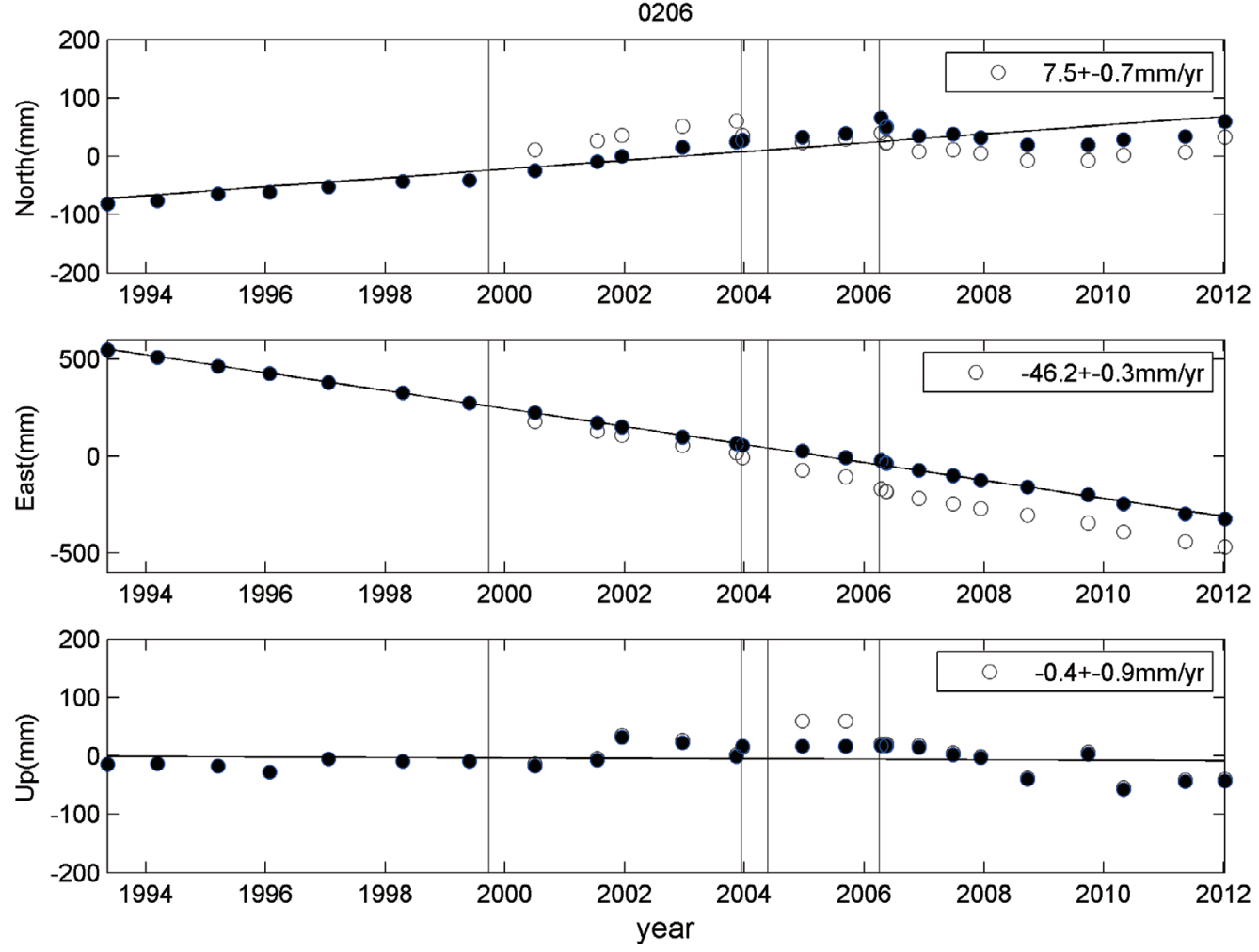

Fig. 6. Examples of campaigned GPS time series (open circles) and calibration after removing earthquake effects (black solid circles) for station 0206 inside the Longitudinal Valley.
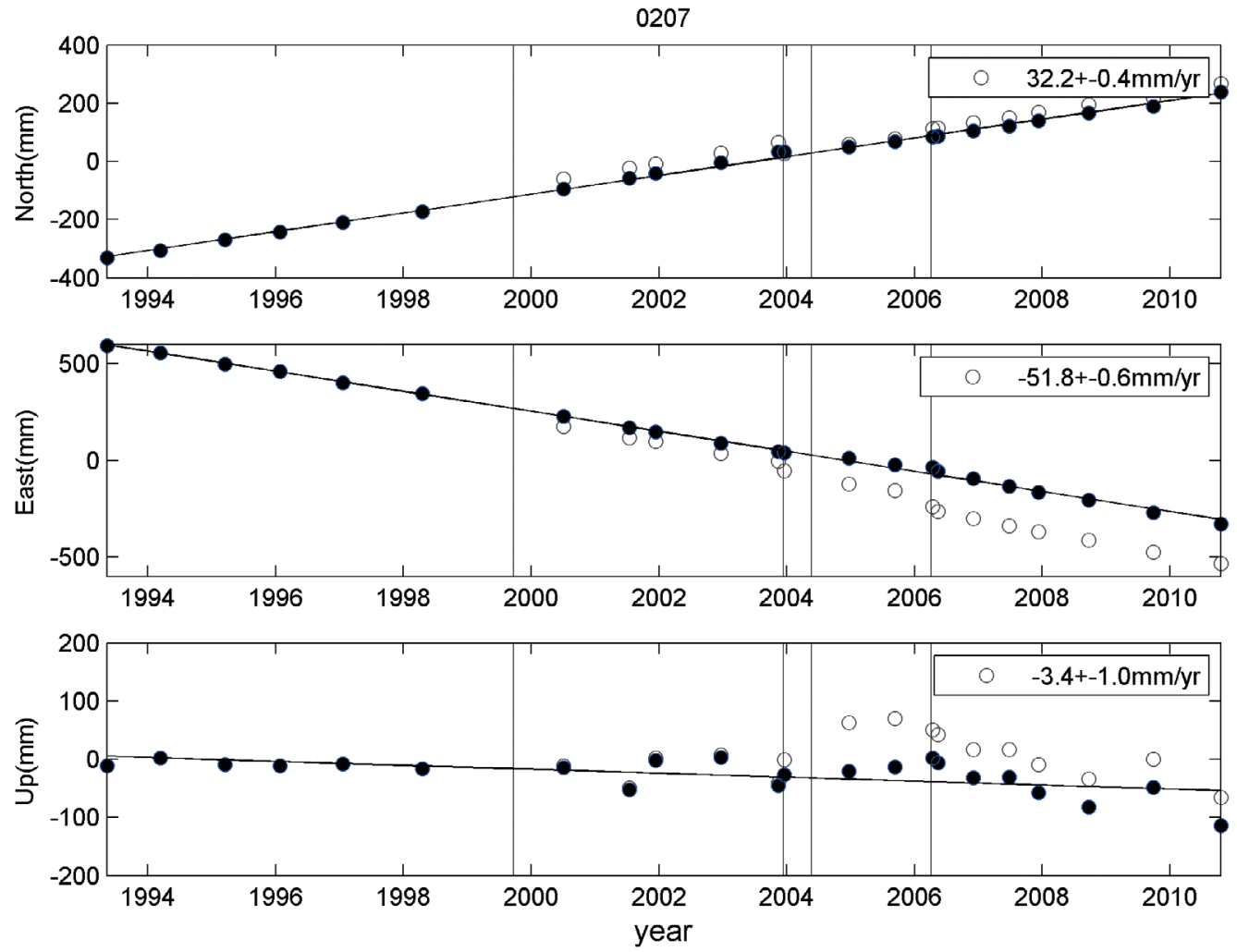

Fig. 7. Examples of campaigned GPS time series (open circles) and calibration after removing earthquake effects (black solid circles) for station 0207 in the western side of Coastal Range. 

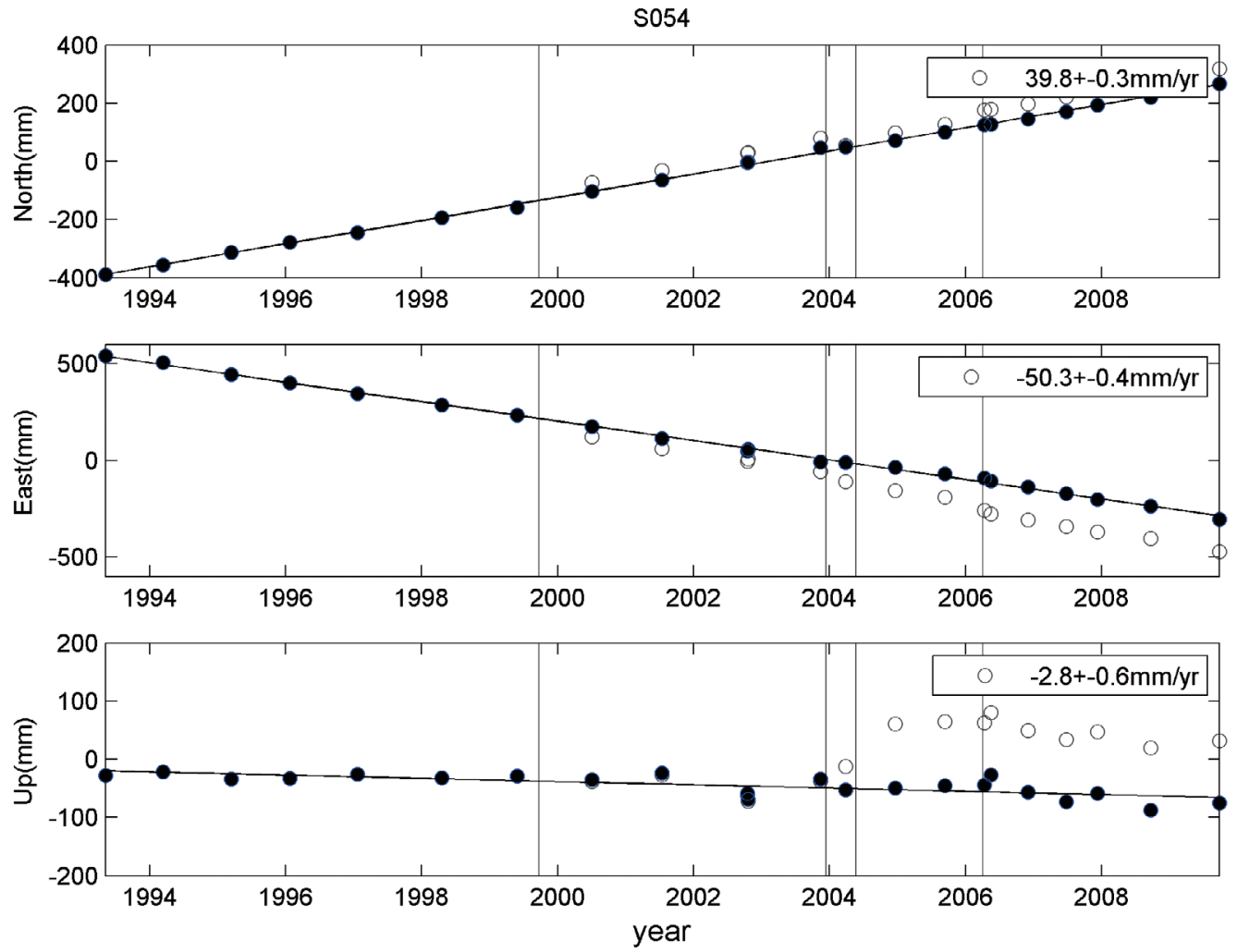

Fig. 8. Examples of campaigned GPS time series (open circles) and calibration after removing earthquake effects (black solid circles) for station S054 in the eastern side of Coastal Range.

Table 3. ITRF2005 velocities of CMS in the southernmost Longitudinal Valley area, southeastern Taiwan.

\begin{tabular}{ccccccc}
\hline Station & Lat $\left(^{\circ}\right)$ & Lon $\left(^{\circ}\right)$ & $\mathbf{N}\left(\mathbf{m m ~ y r}^{-1}\right)$ & $\mathbf{E}\left(\mathbf{m m} \mathbf{y r}^{-1}\right)$ & Data period $(\mathbf{y r})$ & Data num. \\
\hline 0206 & 22.8117 & 121.1012 & $-8.4 \pm 0.8$ & $-21.3 \pm 0.3$ & $1993.3-2012.0$ & 26 \\
\hline 0207 & 22.8196 & 121.1395 & $17.1 \pm 0.2$ & $-27.1 \pm 0.5$ & $1993.3-2009.7$ & 21 \\
\hline 0211 & 22.7553 & 121.1340 & $-5.4 \pm 0.6$ & $-15.7 \pm 0.3$ & $1993.3-2010.7$ & 22 \\
\hline 0308 & 22.9440 & 121.1528 & $6.9 \pm 0.7$ & $-7.9 \pm 1.2$ & $1997.0-2009.7$ & 16 \\
\hline 0943 & 22.7793 & 121.1383 & $-12.3 \pm 1.4$ & $-18.2 \pm 0.5$ & $2006.6-2010.7$ & 7 \\
\hline 8049 & 22.9476 & 121.1290 & $10.3 \pm 0.7$ & $-2.9 \pm 0.9$ & $1997.0-2009.7$ & 18 \\
\hline 8050 & 22.9269 & 121.1361 & $10.1 \pm 0.7$ & $-5.5 \pm 0.7$ & $1997.0-2009.7$ & 18 \\
\hline 8052 & 22.8950 & 121.1275 & $4.8 \pm 2.9$ & $-19.6 \pm 1.6$ & $2006.3-2010.7$ & 7 \\
\hline 8058 & 22.8356 & 121.0858 & $-17.9 \pm 2.8$ & $-18.8 \pm 1.0$ & $2006.3-2010.7$ & 7 \\
\hline 9171 & 22.9525 & 121.1209 & $3.6 \pm 2.8$ & $-1.0 \pm 5.9$ & $2001.9-2004.9$ & 5 \\
\hline 9172 & 22.9336 & 121.1371 & $5.2 \pm 1.3$ & $0.5 \pm 0.9$ & $2001.9-2009.7$ & 11 \\
\hline 9176 & 22.9014 & 121.0920 & $-8.3 \pm 2.4$ & $-3.9 \pm 1.8$ & $2006.3-2010.7$ & 7 \\
\hline 9179 & 22.8657 & 121.0866 & $-12.9 \pm 3.3$ & $-6.6 \pm 1.4$ & $2006.3-2010.7$ & 7 \\
\hline 9184 & 22.7877 & 121.1073 & $-12.6 \pm 2.5$ & $-21.0 \pm 1.5$ & $2006.3-2010.7$ & 7 \\
\hline 9190 & 22.7633 & 121.0505 & $-14.0 \pm 3.6$ & $-4.7 \pm 2.3$ & $2007.4-2010.7$ & 5 \\
\hline $205 \mathrm{R}$ & 22.7818 & 121.1568 & $18.1 \pm 1.4$ & $-29.1 \pm 1.4$ & $2006.3-2010.7$ & 7 \\
\hline
\end{tabular}


Table 3. (Continued)

\begin{tabular}{|c|c|c|c|c|c|c|}
\hline Station & Lat $\left(^{\circ}\right)$ & Lon $\left({ }^{\circ}\right)$ & $\mathbf{N}\left(\mathbf{m m} \mathbf{y r}^{-1}\right)$ & $\mathbf{E}\left(\mathbf{m m} \mathbf{y r}^{-1}\right)$ & Data period $(\mathrm{yr})$ & Data num \\
\hline $38 \mathrm{R} 2$ & 22.7932 & 121.1326 & $-22.8 \pm 2.2$ & $-13.3 \pm 2.3$ & $2006.3-2009.7$ & 6 \\
\hline A089 & 22.7677 & 121.1561 & $-12.6 \pm 2.9$ & $-24.9 \pm 5.5$ & $2006.3-2010.7$ & 7 \\
\hline A091 & 22.7383 & 121.1137 & $-11.8 \pm 1.3$ & $-21.4 \pm 1.0$ & $2006.3-2010.7$ & 7 \\
\hline E322 & 22.7770 & 121.1146 & $-10.4 \pm 2.7$ & $-19.4 \pm 1.3$ & 2006.3 - 2010.7 & 7 \\
\hline I130 & 22.7937 & 121.1507 & $16.0 \pm 1.0$ & $-27.4 \pm 1.2$ & 2006.9 - 2009.7 & 5 \\
\hline I138 & 22.8665 & 121.1012 & $2.8 \pm 1.3$ & $-16.0 \pm 0.5$ & $1997.0-2009.7$ & 16 \\
\hline N623 & 23.0411 & 121.2840 & $34.7 \pm 1.1$ & $-18.0 \pm 1.0$ & 2002.7 - 2009.7 & 11 \\
\hline S040 & 23.0324 & 121.1419 & $-1.0 \pm 0.5$ & $-3.0 \pm 0.6$ & $1993.3-2009.7$ & 21 \\
\hline S044 & 22.6796 & 121.0144 & $-7.8 \pm 0.4$ & $-4.5 \pm 0.3$ & 1992.4 - 2009.7 & 24 \\
\hline S045 & 22.8821 & 121.0724 & $-3.7 \pm 0.5$ & $-4.0 \pm 0.2$ & $1992.4-2009.7$ & 25 \\
\hline S054 & 22.7958 & 121.1894 & $27.1 \pm 0.4$ & $-27.3 \pm 0.4$ & $1993.3-2009.7$ & 22 \\
\hline S056 & 23.0387 & 121.1904 & $25.8 \pm 0.4$ & $-23.5 \pm 0.3$ & $1993.3-2009.7$ & 22 \\
\hline S057 & 22.9748 & 121.3012 & $33.6 \pm 0.5$ & $-22.2 \pm 0.5$ & $1993.3-2009.7$ & 21 \\
\hline S063 & 22.6664 & 121.4704 & $32.7 \pm 0.2$ & $-40.0 \pm 0.2$ & $1993.3-2010.3$ & 21 \\
\hline S072 & 22.9274 & 121.1545 & $27.0 \pm 0.6$ & $-28.2 \pm 0.3$ & $1993.3-2009.7$ & 23 \\
\hline S126 & 22.8919 & 121.1423 & $20.8 \pm 0.7$ & $-29.3 \pm 0.5$ & $1997.0-2009.7$ & 18 \\
\hline S127 & 22.9434 & 121.1444 & $4.6 \pm 0.5$ & $0.8 \pm 1.1$ & $1997.0-2009.7$ & 17 \\
\hline S128 & 22.9420 & 121.1492 & $11.6 \pm 1.1$ & $-1.6 \pm 0.7$ & $1997.0-2009.7$ & 16 \\
\hline S193 & 22.9428 & 121.1608 & $44.4 \pm 1.7$ & $-29.6 \pm 0.6$ & 2001.9 - 2009.7 & 12 \\
\hline S194 & 22.9447 & 121.1560 & $17.1 \pm 1.0$ & $-8.7 \pm 0.6$ & 2001.9 - 2009.7 & 12 \\
\hline S195 & 22.9337 & 121.1278 & $5.3 \pm 1.3$ & $1.4 \pm 1.1$ & 2001.9 - 2009.7 & 12 \\
\hline S196 & 22.9366 & 121.1245 & $5.9 \pm 1.2$ & $2.0 \pm 1.3$ & $2001.9-2009.7$ & 12 \\
\hline S197 & 22.9392 & 121.1201 & $2.3 \pm 1.2$ & $2.5 \pm 1.1$ & 2001.9 - 2009.7 & 10 \\
\hline S198 & 22.9405 & 121.1187 & $0.4 \pm 1.4$ & $2.6 \pm 0.9$ & $2001.9-2009.7$ & 11 \\
\hline S199 & 22.9075 & 121.1277 & $8.3 \pm 2.0$ & $-0.6 \pm 1.9$ & 2001.9 - 2009.7 & 12 \\
\hline S200 & 22.9055 & 121.1171 & $6.5 \pm 1.7$ & $-6.8 \pm 1.0$ & $2001.9-2008.7$ & 11 \\
\hline S201 & 22.9058 & 121.1087 & $6.5 \pm 1.1$ & $-9.7 \pm 0.5$ & 2001.9 - 2009.7 & 11 \\
\hline S203 & 22.9059 & 121.1031 & $-2.8 \pm 1.4$ & $-2.9 \pm 1.0$ & $2001.9-2009.7$ & 12 \\
\hline S206 & 22.9158 & 121.0839 & $-8.1 \pm 1.4$ & $7.1 \pm 2.0$ & 2001.9 - 2008.7 & 10 \\
\hline S207 & 22.9416 & 121.1165 & $-0.5 \pm 1.2$ & $4.5 \pm 1.4$ & 2001.9 - 2009.7 & 13 \\
\hline S209 & 22.9039 & 121.0730 & $-7.8 \pm 1.0$ & $5.0 \pm 1.5$ & $2001.9-2010.7$ & 14 \\
\hline S210 & 22.9531 & 121.1345 & $5.8 \pm 2.8$ & $-3.1 \pm 3.4$ & $2001.9-2004.2$ & 4 \\
\hline S211 & 22.8824 & 121.0868 & $-10.1 \pm 1.7$ & $2.0 \pm 0.9$ & $2001.9-2010.7$ & 13 \\
\hline S212 & 22.8708 & 121.1328 & $19.4 \pm 2.2$ & $-28.3 \pm 0.7$ & 2001.9 - 2009.7 & 11 \\
\hline S213 & 22.9190 & 121.1147 & $6.8 \pm 1.2$ & $-1.4 \pm 0.8$ & $2001.9-2009.7$ & 12 \\
\hline
\end{tabular}


Table 3. (Continued)

\begin{tabular}{|c|c|c|c|c|c|c|}
\hline Station & Lat $\left({ }^{\circ}\right)$ & $\operatorname{Lon}\left({ }^{\circ}\right)$ & $\mathbf{N}\left(\mathbf{m m ~ y r ^ { - 1 } )}\right.$ & $E\left(m m y^{-1}\right)$ & Data period (yr) & Data num. \\
\hline S214 & 22.9648 & 121.2324 & $31.9 \pm 0.5$ & $-17.7 \pm 0.8$ & 2002.7 - 2009.7 & 12 \\
\hline S215 & 22.8758 & 121.1025 & $0.1 \pm 2.1$ & $-15.4 \pm 0.7$ & 2001.9 - 2009.7 & 12 \\
\hline S216 & 22.8732 & 121.1140 & $3.2 \pm 1.8$ & $-21.2 \pm 0.6$ & 2001.9 - 2009.7 & 13 \\
\hline S217 & 22.8698 & 121.1353 & $24.1 \pm 1.3$ & $-27.9 \pm 0.6$ & 2001.9 - 2009.7 & 11 \\
\hline S218 & 22.8676 & 121.1488 & $27.7 \pm 1.1$ & $-21.9 \pm 0.5$ & 2001.9 - 2009.7 & 13 \\
\hline S219 & 22.8792 & 121.1097 & $0.7 \pm 1.7$ & $-16.9 \pm 0.7$ & $2001.9-2009.7$ & 13 \\
\hline S221 & 22.9301 & 121.2608 & $33.2 \pm 0.7$ & $-22.6 \pm 0.9$ & 2002.7 - 2009.7 & 13 \\
\hline S230 & 23.0359 & 121.1712 & $2.6 \pm 0.6$ & $-0.7 \pm 1.0$ & $2002.7-2010.7$ & 12 \\
\hline S231 & 23.0409 & 121.1649 & $-1.0 \pm 0.5$ & $4.4 \pm 1.3$ & 2002.7 - 2009.7 & 12 \\
\hline S232 & 22.9448 & 121.2090 & $31.7 \pm 0.6$ & $-16.2 \pm 1.2$ & $2002.7-2009.7$ & 12 \\
\hline S233 & 23.0458 & 121.1517 & $-1.4 \pm 0.8$ & $8.2 \pm 1.2$ & 2002.7 - 2009.7 & 11 \\
\hline S237 & 22.8995 & 121.1414 & $11.5 \pm 1.3$ & $-21.2 \pm 0.6$ & $2003.8-2009.7$ & 11 \\
\hline S238 & 22.9059 & 121.1063 & $2.7 \pm 0.8$ & $-8.1 \pm 0.8$ & 2003.8 - 2009.7 & 9 \\
\hline S239 & 22.9071 & 121.0933 & $-12.8 \pm 1.3$ & $-1.5 \pm 2.8$ & $2003.8-2009.7$ & 11 \\
\hline S240 & 22.9009 & 121.0539 & $-10.3 \pm 1.0$ & $3.9 \pm 1.9$ & $2003.8-2010.7$ & 12 \\
\hline S245 & 22.9808 & 121.1292 & $-2.6 \pm 1.3$ & $-1.0 \pm 0.9$ & $2004.9-2010.7$ & 9 \\
\hline S246 & 22.9758 & 121.1567 & $-1.3 \pm 1.2$ & $2.9 \pm 2.3$ & 2005.6 - 2009.7 & 7 \\
\hline S248 & 22.9773 & 121.1786 & $32.9 \pm 1.3$ & $-24.7 \pm 0.8$ & $2004.9-2010.7$ & 9 \\
\hline S260 & 22.8026 & 121.0865 & $-19.7 \pm 2.8$ & $-10.9 \pm 1.8$ & 2006.3 - 2010.7 & 7 \\
\hline S262 & 22.8171 & 121.0888 & $-17.1 \pm 2.9$ & $-20.6 \pm 1.2$ & $2006.3-2010.7$ & 7 \\
\hline S263 & 22.8257 & 121.0921 & $-19.0 \pm 3.5$ & $-24.2 \pm 1.5$ & $2006.3-2010.7$ & 7 \\
\hline S264 & 22.7620 & 121.1471 & $-7.9 \pm 1.7$ & $-20.5 \pm 1.2$ & $2006.3-2010.7$ & 7 \\
\hline S265 & 22.8065 & 121.1169 & $-23.7 \pm 1.5$ & $-22.3 \pm 2.0$ & 2006.3 - 2009.7 & 7 \\
\hline S266 & 22.7860 & 121.1200 & $-15.7 \pm 2.5$ & $-17.9 \pm 1.0$ & $2006.4-2010.7$ & 8 \\
\hline S267 & 22.7917 & 121.1294 & $-16.9 \pm 2.4$ & $-20.7 \pm 1.8$ & 2006.3 - 2010.7 & 7 \\
\hline S270 & 22.7739 & 121.1026 & $-16.5 \pm 0.8$ & $-21.2 \pm 1.6$ & $2006.3-2009.7$ & 6 \\
\hline S271 & 22.7564 & 121.1101 & $-10.5 \pm 3.0$ & $-18.5 \pm 0.8$ & 2006.3 - 2010.7 & 8 \\
\hline S272 & 22.7929 & 121.0689 & $-17.8 \pm 2.2$ & $-13.6 \pm 2.1$ & $2006.3-2010.7$ & 7 \\
\hline S273 & 22.7671 & 121.0547 & $-17.0 \pm 3.1$ & $-13.3 \pm 0.8$ & $2006.3-2010.7$ & 7 \\
\hline S274 & 22.7804 & 121.1005 & $-20.2 \pm 1.2$ & $-21.8 \pm 1.7$ & $2006.0-2009.7$ & 8 \\
\hline S280 & 22.7924 & 121.0453 & $-11.6 \pm 2.8$ & $-5.0 \pm 1.1$ & $2006.6-2010.7$ & 7 \\
\hline V108 & 22.9757 & 121.1491 & $-1.8 \pm 0.8$ & $2.0 \pm 0.8$ & $2003.8-2009.7$ & 9 \\
\hline V109 & 22.9747 & 121.1663 & $14.9 \pm 1.8$ & $-17.3 \pm 0.7$ & $2003.8-2009.7$ & 9 \\
\hline V171 & 22.8455 & 121.1004 & $-9.7 \pm 2.3$ & $-22.3 \pm 0.8$ & $2006.3-2010.7$ & 7 \\
\hline W048 & 22.9031 & 121.1457 & $19.6 \pm 2.0$ & $-25.0 \pm 0.7$ & $2003.8-2009.7$ & 11 \\
\hline
\end{tabular}




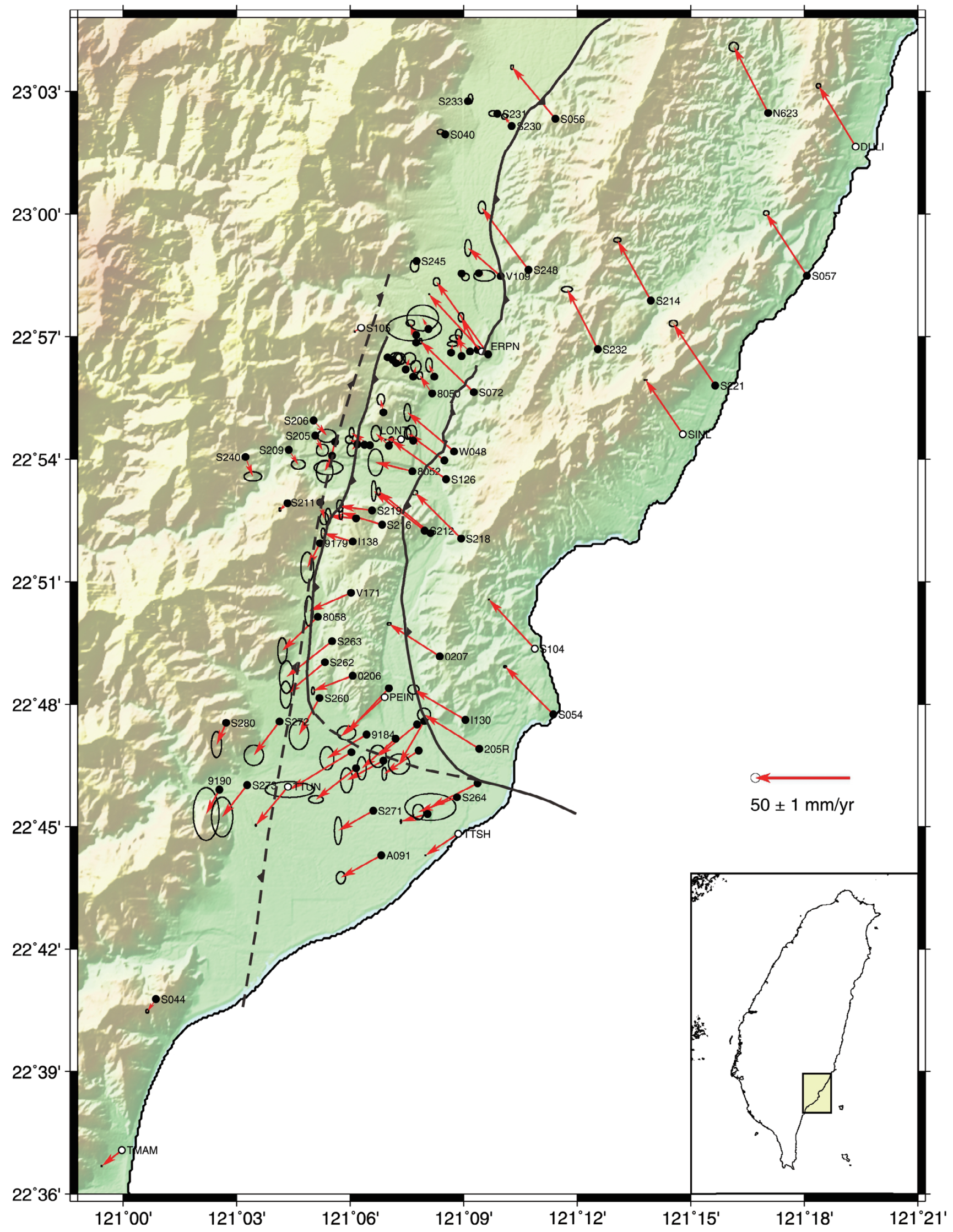

Fig. 9. Results of our revised velocity field from the dense GPS array in the southernmost Longitudinal Valley area, relative to the ITRF 2005 reference frame. See Table 1 for detailed station velocity and other relevant information. 


\section{STRAIN RATES}

In order to better characterize the inter-seismic surface deformation, we calculated the horizontal strain rates based on the 96 GPS station velocities (86 CMS and 10 CORS), by applying interpolation method as continuous functions for the whole monitoring area (Frank 1966; Prescott 1976; Prescott et al. 1979, Shen et al. 1996). We adopted the algorithm of Shen et al. (1996) to calculate both dilatation strain rate and shear strain rate. In practice, we set a mesh of grids with a spacing of $2 \times 2 \mathrm{~km}$ in the study area. The strain rates of each node were determined by distance-weighting the neighboring GPS stations with minimum 4 stations. The dilatation/ shear strain rates with the associated principal strain axes were thus obtained and are illustrated in Fig. 10. Note that we adopt the positive sign for extension and negative sign for shortening in the expression of dilatation strain rate.

First for the Lichi Fault, we find that a dramatic change of dilatation strain rate occurs along the Lichi Fault (Fig. 10a): strong NW-SE shortening $\left(-4 \sim-9 \mu\right.$ strain $\left.\mathrm{yr}^{-1}\right)$ in the northern part and substantial NNE-SSW extension $\left(0-4 \mu\right.$ strain $\left.\mathrm{yr}^{-1}\right)$ around the southern part of the fault. We can also observe that the peak of the shear strain of the area (up to $6 \mu$ strain $\mathrm{yr}^{-1}$ ) occurs along the northern part of the Lichi Fault (Fig. $10 \mathrm{~b})$, and in effect substantial shear strain occurs all along the fault. In terms of the orientations of the principal shear strain axes (Fig. 10b), the left-lateral strain axes are at a small to moderate angle (about $15^{\circ}-30^{\circ}$ ) to the fault strike, suggesting that an oblique left-lateral shearing occurs in the northern Lichi Fault. On the other hand, the southern part of the fault shows a very small angle between strain axes and fault strike $\left(<10^{\circ}\right)$, indicating a nearly pure left-lateral shearing with increasing extension toward the south. In summary, it implies that the northern Lichi Fault is experiencing a transpression (i.e., shortening and oblique left-lateral shearing) strain and the southern part is experiencing a transtension strain (i.e., left-lateral shearing and extension).

Along the northern and middle part of the Luyeh Fault, where its surface trace juxtaposes closely with that of the Central Range Fault on the western side of the Peinanshan massif, the surface deformation exhibits moderate NW to WNW shortening (Fig. 10a) and moderate, oblique left-lateral shearing (Fig. 10b). Based on this $2 \times 2 \mathrm{~km}$ grid strain analysis, it is difficult, if not impossible, to differentiate the strain between the Luyeh Fault and the Central Range Fault. In this study, we tend to attribute the surface deformation mainly to the Luyeh Fault. Around the southern part of the Luyeh Fault we interpret that the fault turns nearly 90 degrees along the southern edge of the Peinanshan massif mainly for the following reasons. We can find that an E-W trending narrow zone of moderate shortening appears to be around the anticipated surface trace of the fault. Combining that it also shows a relatively low shear strain (Fig. 10b), this zone reveals oblique shortening with minor left-lateral shear.
Elsewhere in the study area, we can also observe some interesting features, for instance, the Coastal Range showing a change from moderate shortening to the north to a moderate extension to the south with a very low shear strain everywhere. However, it is difficult to draw any conclusion at this stage because of poor coverage of GPS stations within the Coastal Range.

\section{ACTIVE FAULT TRACES AND NEAR-FAULT SURFACE DEFORMATION}

In this section, we describe near-fault surface deformation in more detail, based on the GPS vectors at the nearby stations along the major active faults in the study area. We aim at not only better defining the location of the surface trace of the major active faults, but also better characterizing the near-fault fault kinematics and slip behaviour. In order to do so, we also projected the station velocities across the major faults in two components (directions): perpendicular and parallel to the fault strike. We selected three sub-areas, from north to south (see location in Fig. 1): (i) northern Luyeh, (ii) Longtien-Peinanshan and (iii) Taitung Plain, as examples to illustrate the near-fault surface deformation, including the one-fault segment (i.e., the southern end of the Chihshang Fault) and two-fault segment (i.e., the Lichi Fault and the Luyeh Fault) for the LVF, together with the seemingly blind Central Range Fault. Five profiles in the EW direction and one profile in the NS direction were presented to analyse the movement characteristics.

\subsection{Northern Luyeh Area}

The northern Luyeh area represents the transition zone where the single-fault system (i.e., the Chihshang Fault) becomes two-fault system toward the south (i.e., the Luyeh Fault to the west of the Peinanshan massif and the Lichi Fault to the east) (Fig. 11). The southern Chihshang Fault appears to end at a two-step small mount (so called Er-Tzeng Ping corresponding this translation in Chinese) in the toe of a large alluvial fan of the Luliao River coming from the Central Range. The two geomorphic scarps imply a twobranch fault system, noting that the two sub-parallel scarps are about $200 \mathrm{~m}$ apart from each other. Indeed, recent levelling data (Chen et al. 2012) indicated significant changes of elevation rates across both scraps $\left(10-12 \mathrm{~mm} \mathrm{yr}^{-1}\right.$ for the western scarp and $20-25 \mathrm{~mm} \mathrm{yr}^{-1}$ for the eastern one).

We conducted kinematics analysis of near fault surface deformation by plotting the GPS station vectors parallel and perpendicular to the fault strike. The GPS stations in this area are divided into two sub-parallel profiles: the Rueyfong profile to the north ( 7 stations) and the YongAn-Rueyuan profile to the south (17 stations). The Rueyfong profile (Fig. 11b) is constituted by 7 GPS stations along an E-W line across the Baohua Bridge, including stations S245 (near the foot of 
the Central Range), V108, S246 (in the Longitudinal Valley), V109, S248, S214 and S057 (in the Coastal Range). Along the profile from west to east, there is little difference in the westernmost three station velocities. Further east, we can observe that stations S246 and V109, which are located on the both sides of Baohua Bridge across the LVF (Chihshang Fault), reveal a dramatic change of the GPS vectors, both in parallel and perpendicular components. Then from V109 to S248, on the immediate of the hanging wall of the LVF in the west side of the Coastal Range, we found there was a significant increase of displacements at the distance of about $1.4 \mathrm{~km}$, implying a continuous increase of slip on the fault plane toward the depth at the uppermost $1-2 \mathrm{~km}$ level. In the projected velocity of Fig. 11b, we can find that the differences of parallel and perpendicular components are 34 and $22 \mathrm{~mm} \mathrm{yr}^{-1}$, respectively, across the LVF, indicating an oblique left-lateral thrusting along the Chihshang Fault at this place.

The YongAn-Rueyuan profile across the northernmost Kaotai terrace and the Er-Tzeng Ping small mount is composed of 17 GPS stations (Fig. 11c) distributed in the transition zone of the single-fault and two-fault systems. As described above, at first glance, we found significant velocity changes across the Chihshang Fault along the two geomorphic scarps in the Er-Tseng Ping small mount. By contrast, the surface deformation across the presumably northernmost part of the Luyeh Fault was quite obscure. In the fault-parallel component (along-strike), projected GPS velocities show a very slow, gradual increase in the rate of $10 \mathrm{~mm} \mathrm{yr}^{-1}$ across the Luyeh terrace (i.e., in the hanging wall of the Luyeh Fault), and a higher rate with a difference of $35 \mathrm{~mm} \mathrm{yr}^{-1}$ in the Longitudinal Valley. In the faultperpendicular (across-strike) component (lower graph of Fig. 11c), the motion is similar to the fault-parallel component: a gradual increase of $8 \mathrm{~mm} \mathrm{yr}^{-1}$ across the Luyeh terrace, and a $30 \mathrm{~mm} \mathrm{yr}^{-1}$ of difference in the Longitudinal Valley. In summary, the Luyeh Fault seems to show some but limited movements in the very northern part of the Peinanshan massif. On the other hand, the southern end of the Chihshang Fault reveals a rapid creep near the surface along the two geomorphic scarps of the Er-Tzeng Ping. Both scarps are tectonically active and characterized by oblique left-lateral thrusting, whereas the eastern one appears to be more active with a more rapid slip rate (i.e., about two times more rapid than the western one).

\subsection{Longtien-Peinanshan Area}

This area is located in the middle part of the two-fault system of the LVF together with the Central Range Fault, which seemingly juxtaposes the Luyeh Fault near the surface. In this area, the Luyeh River flows toward the east in the middle and cuts through the uplifted Quaternary fluvial deposits of the Kaotai/Longtien tableland to the north and the Peinanshan tableland to the south. Previous studies, including geological mapping and geodetic leveling measurements (e.g., Yu et al. 1990; Lee et al. 1998; Shyu et al. 2008; Chen et al. 2012), revealed that the surface trace of the Luyeh Fault follows closely the geological boundary between the Central Range and the uplifted late Quaternary terrace deposits (i.e., the Kaotai and Peinanshan tablelands) (Fig. 12a). On the other hand, the Lichi Fault, representing the major fault along which the Coastal Range is thrust over the late Quaternary Peinanshan massif, seems to cut through into the eastern side of the northern Peinanshan tableland, according to leveling data (Chen et al. 2012) (Fig. 12a). However, the detailed location of its surface traces remains still questionable, because of the resolution of benchmark coverage. In this section, we shall describe how we better localize the surface trace of the Lichi Fault in this area based on combining the GPS horizontal velocities.

From the GPS velocities in map view (Fig. 12a), we found that the yielded surface trace of the Luyeh Fault is consistent with the previous mapped locations and that the Lichi Fault indeed cuts into eastern edge of the Longtien terraces and the Peinanshan tableland. As for the analyses of the projected profiles of the GPS vectors across the major faults, we divided the stations into two sub-parallel profiles: the Longtien profile to the north of the Luyeh River (Fig. 12b) and the northern Peinanshan profile to the south (Fig. 12c). The Longtien profile is composed of 14 GPS stations, from west to east: 4 stations in the Central Range (S240, S209, S206, S205), 7 stations in the Longtien tableland (S239, S203, S238, S201, S200, LONT, S199), 3 stations in the western edge of the Coastal Range (S237, S126 and W048). In the profile of Fig. 12b, we can observe a graduate increase of velocities of about 11 and $15 \mathrm{~mm} \mathrm{yr}^{-1}$ in fault-parallel and fault-perpendicular components, respectively, across the Luyeh Fault particularly in the hanging wall of the fault at a distance of about $1 \mathrm{~km}$ from the fault, implying the Luyeh Fault is partially locked near the surface or a significant decrease of slip toward the surface. Across the Lichi Fault, there is a difference of 8 and $27 \mathrm{~mm} \mathrm{yr}^{-1}$ in the fault-parallel and fault-perpendicular components, respectively (Fig. 12b), indicating a dominant thrust with minor left-lateral component for the inter-seismic creep of the Lichi Fault to the north of the Luyeh River.

Projected velocities of the stations across the faults in northern Peinanshan tableland profile are shown in Fig. 12c, from west to east: 3 stations in the Central Range (S045, S211, 9179), 6 stations in the Peinanshan tableland (S215, S219, I138, S212 and S217), and one station (S218) in the Coastal Range. First across the Luyeh Fault, the faultparallel and fault-perpendicular velocities show a gradual increase of velocity of 10 and $20 \mathrm{~mm} \mathrm{yr}^{-1}$, respectively, in the hanging wall of the fault. On the other hand they show an increase of velocity of 22 and $12 \mathrm{~mm} \mathrm{yr}^{-1}$, in fault-parallel and fault-perpendicular components, respectively, across the Lichi Fault (Fig. 12c). Our results indicate that the Lichi 
(a)

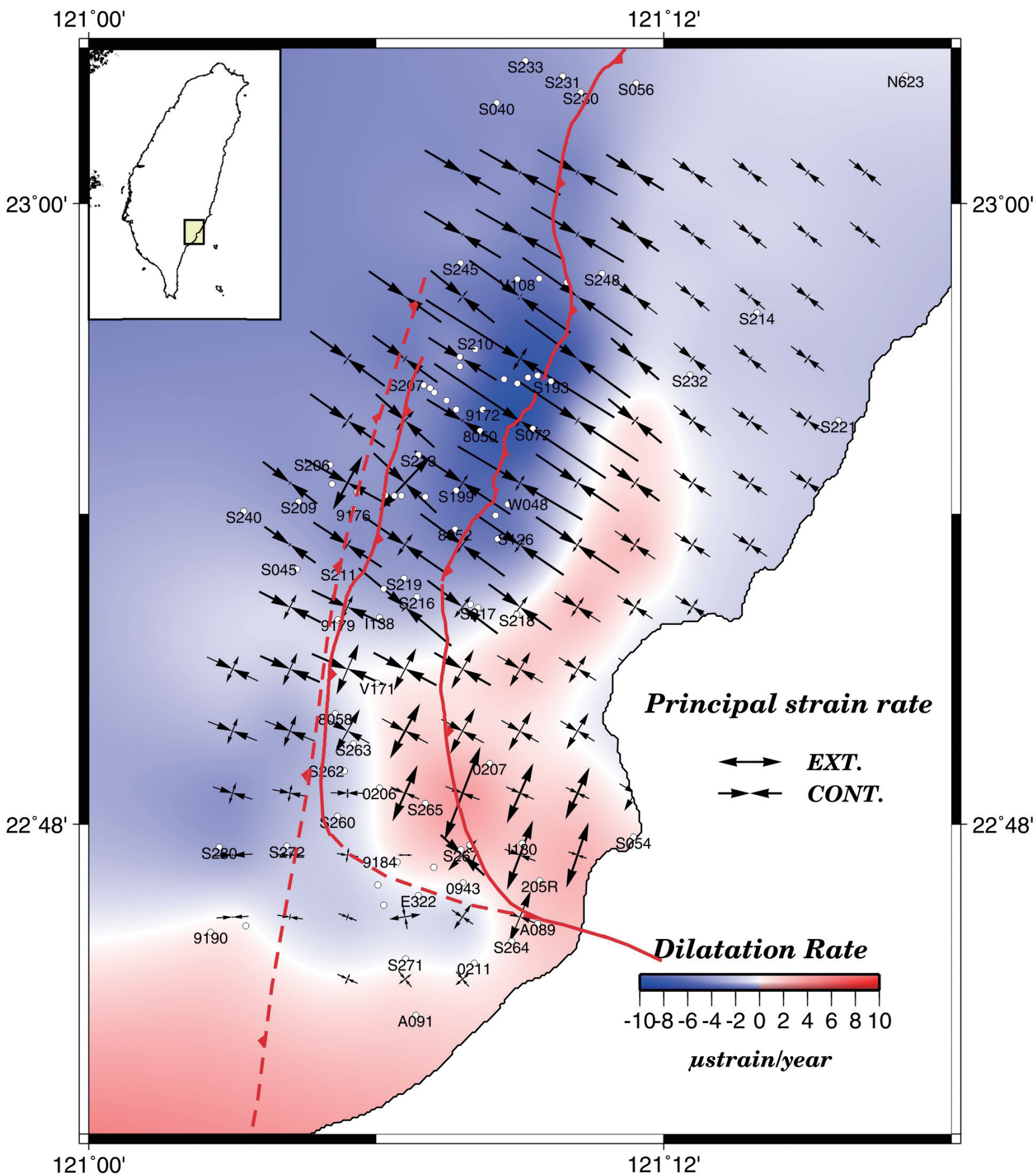

Fig. 10. (a) Dilation strain rate with the associated principal strain axes. (b) Shear strain rate and the principal left-lateral strain axes. Note that the right-lateral strain axes, which are not shown for the sake of simplicity, are perpendicular to the left-lateral strain axes. Significant strain, including dilatation and shear strain, is closely related to the three major active faults in the study area. See the main text for more detailed descriptions. 
(b)

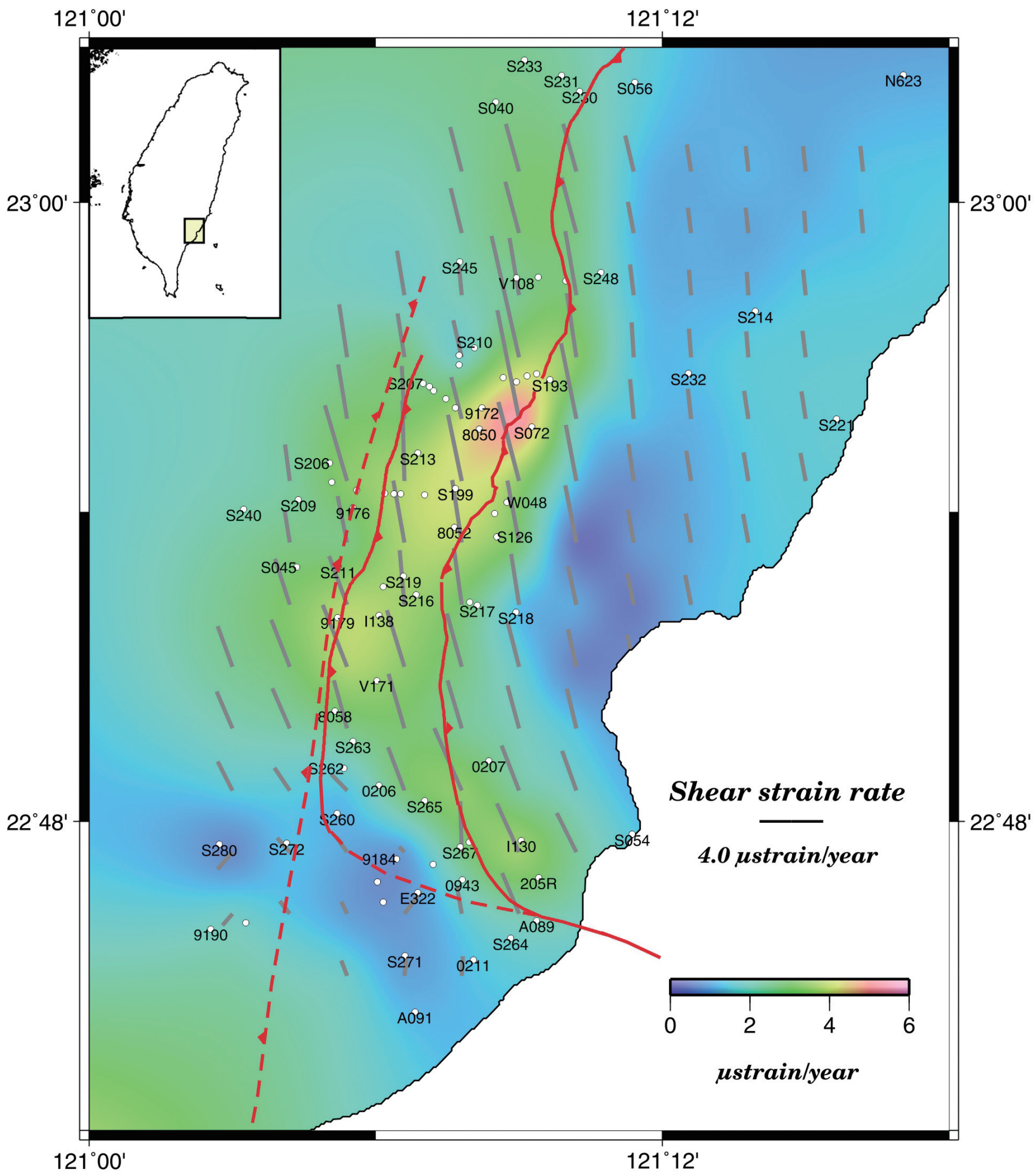


(a)

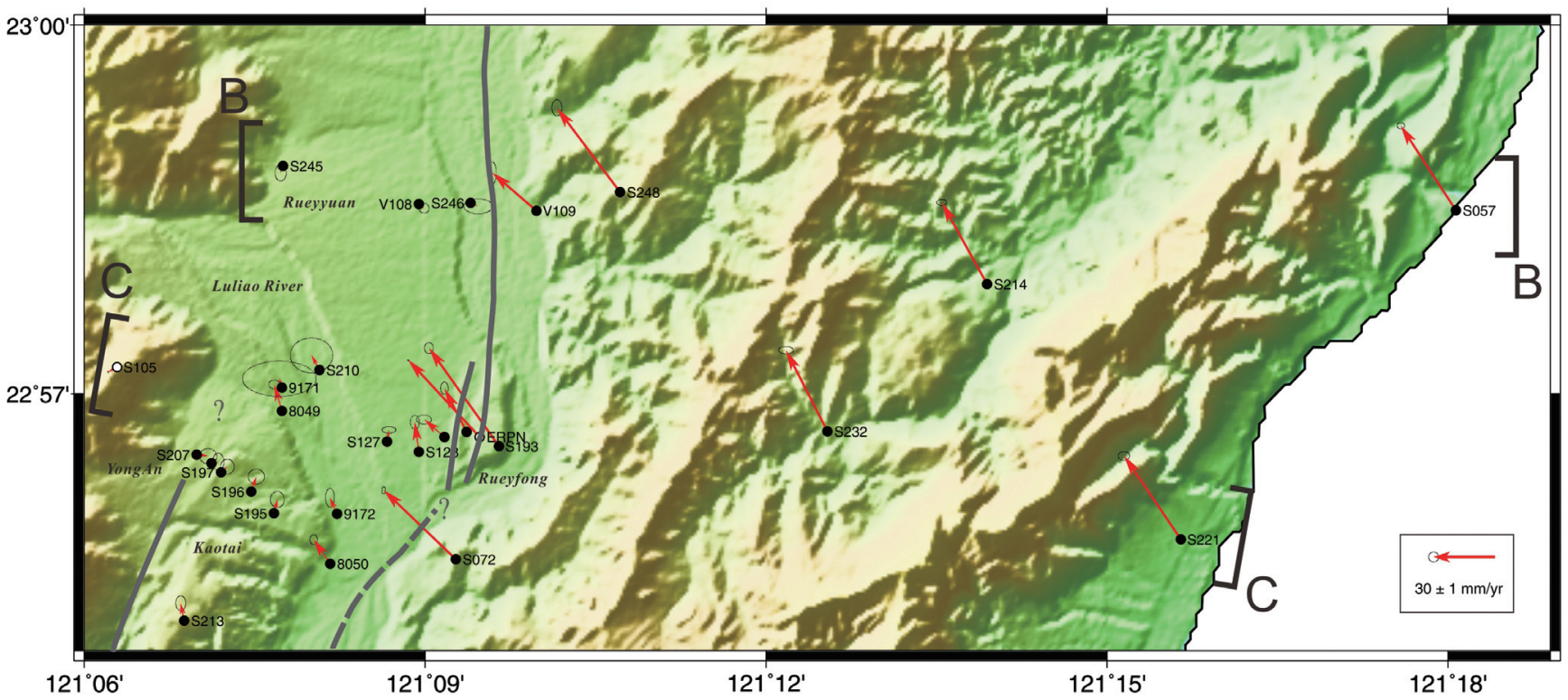

(b)
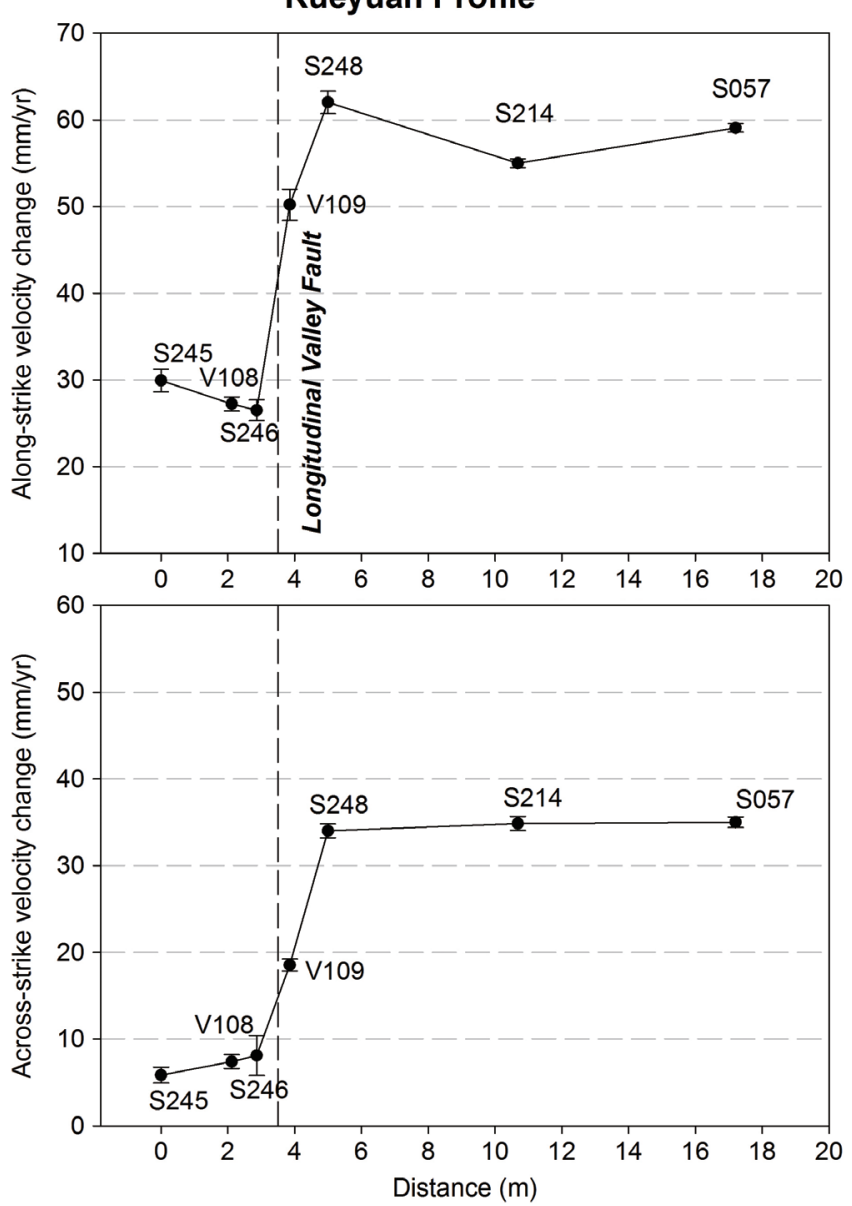

(c)
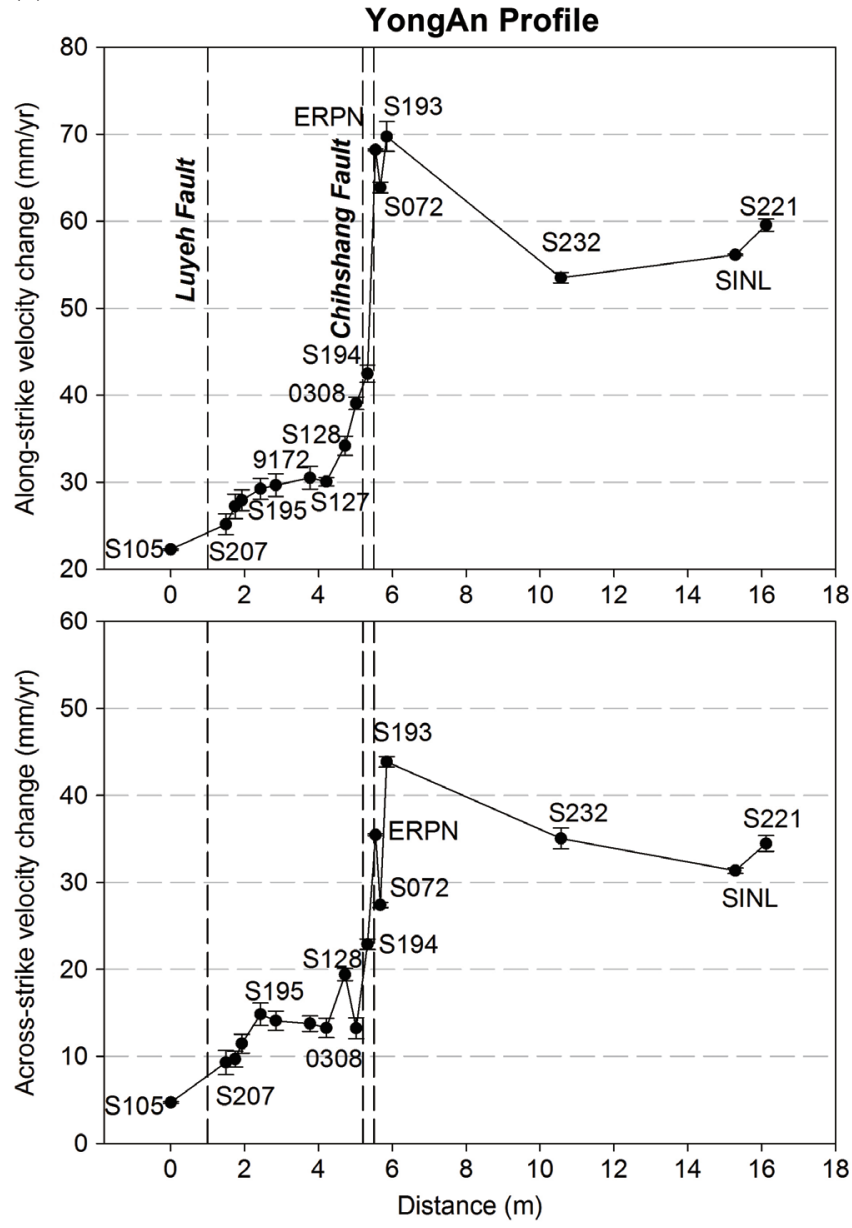

Fig. 11. Near fault surface deformation in Rueyfong (one-fault system), YongAn and Rueyuan (two-fault system) areas. Station velocities projected to the parallel and normal directions of the strike of the LVF for the two profiles: Rueyfong profile to the north and YongAn and Rueyuan profile to the south. The surface traces of the faults are shown as heavy lines. See the main text for more detailed analyses and descriptions. 


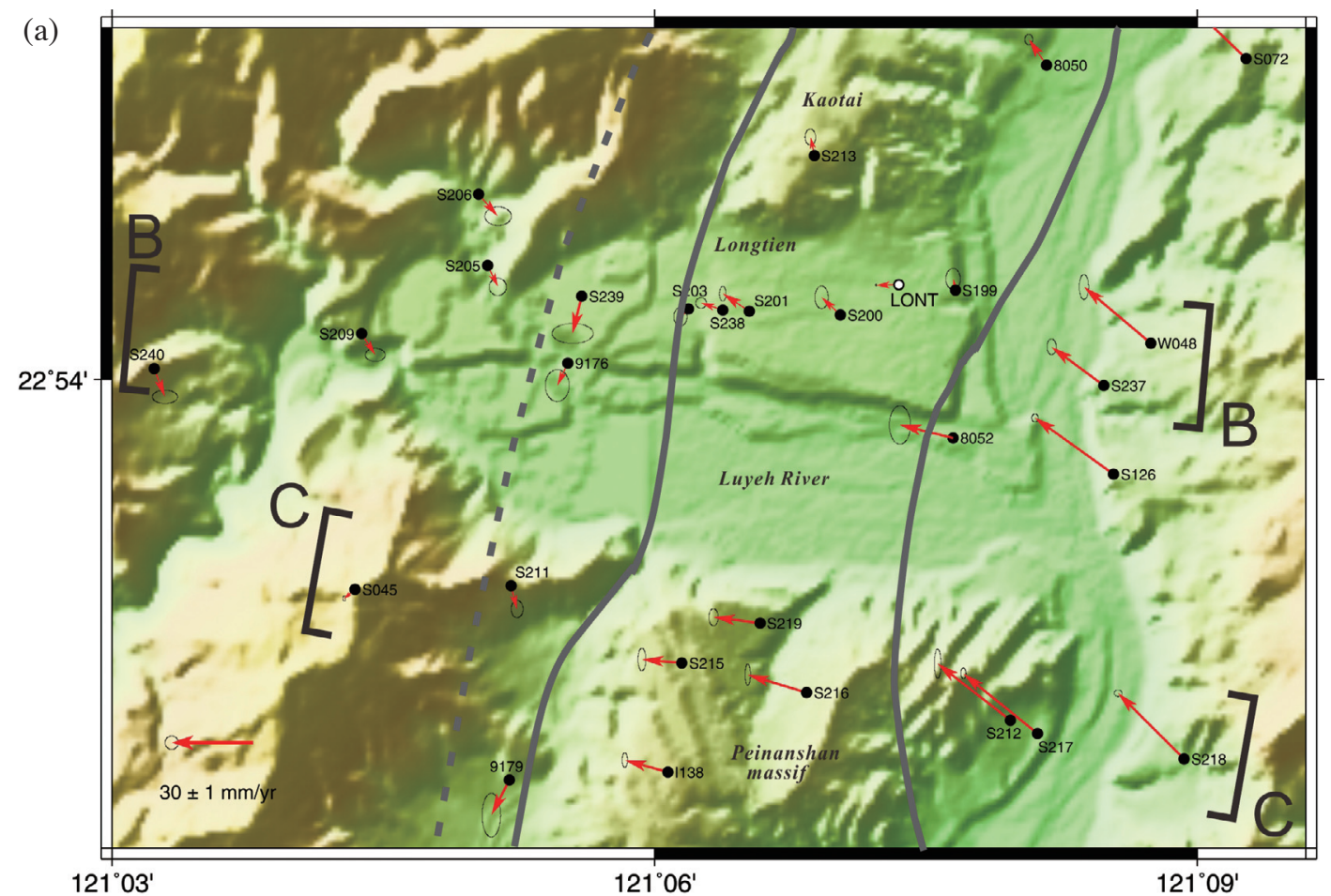

(b)
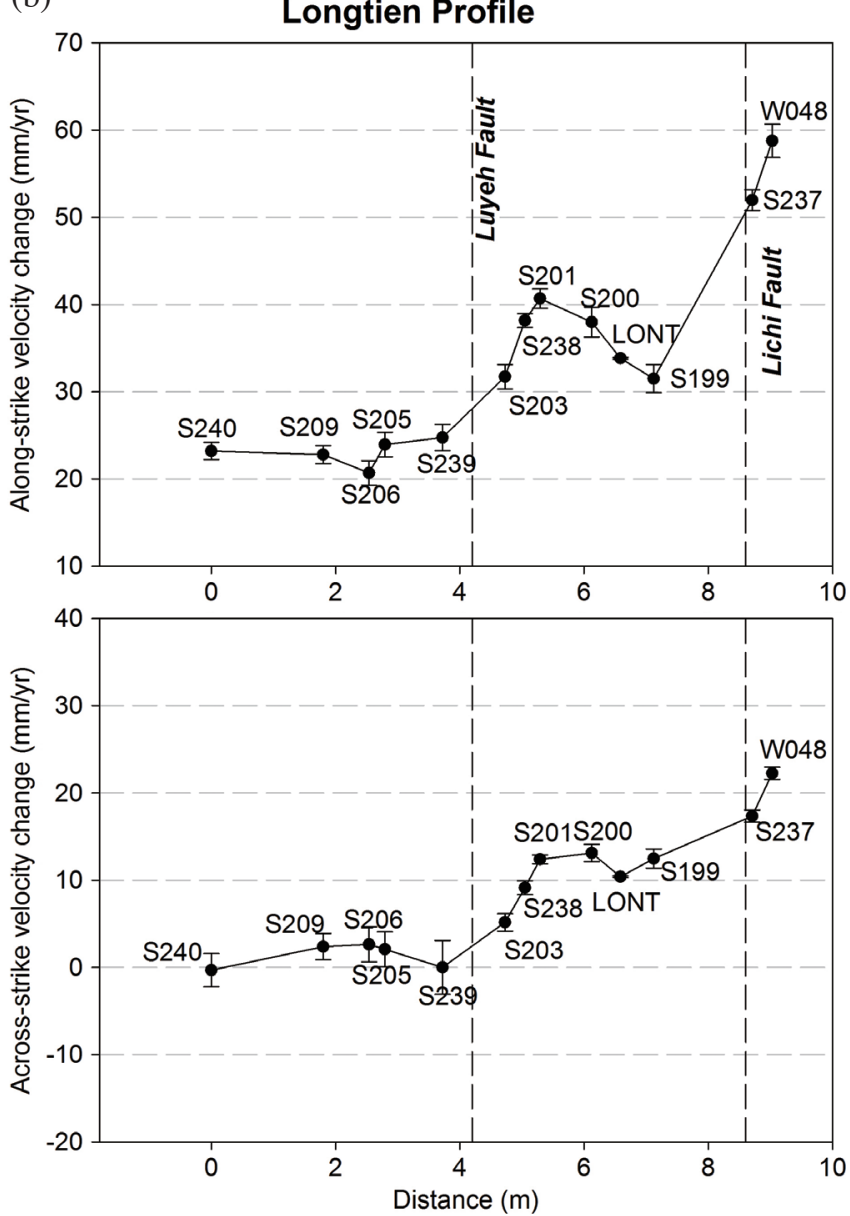

(c)
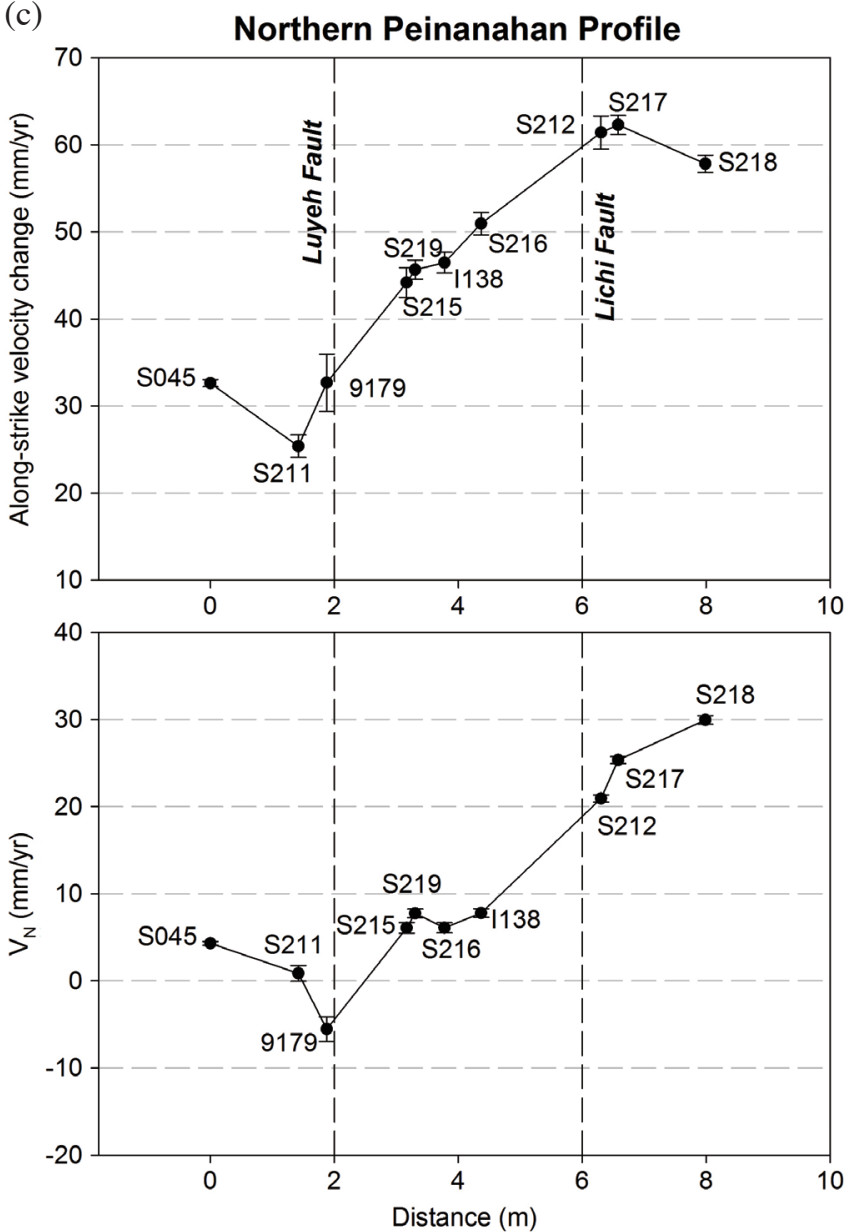

Fig. 12. Near fault surface deformation in Longtien-northern Peinanshan area. Station velocities projected to the parallel and normal directions of the strike of the LVF for the two profiles: Longtien profile in the north and Northern Peinanshan profile in the south. The surface trace of the faults are derived and shown as heavy lines. 
Fault reveals a more significant strike-slip motion than thrust motion to the south of the Luyeh River, which also has been illustrated from the strain analyses in the earlier section.

Comparing the Longtien and northern Peinanshan profiles, we find a clear difference of fault kinematics for the LVF system between the two areas. There are more dramatic changes of velocities across the Luyeh Fault in the north than those in the south. This suggests that the fault coupling of the Luyeh Fault is higher to the south of the Luyeh River compared to the segment to the north of the Luyeh River. It thus deserves to conduct a more sophisticated kinematic numerical modelling, such as elastic dislocation modelling to better understand the subsurface fault slip distribution along the major faults.

It is also worth noting that the surface deformation due to inter-seismic slip on the Central Range Fault, whose surface projection would be quite close to the Luyeh Fault, was difficult to differentiate from that on the Luyeh Fault based on our results of the inter-seismic GPS displacements. On the other hand, we do observe a little difference of slip behaviours between two profiles on the both sides of the Luyeh River. In the southern profile, we can find a rather sharp change of velocity around the anticipated surface projection of the Central Range Fault. It implies that the eastvergent thrusting of the Central Range Fault becomes more evident to the south of the Luyeh River.

\subsection{Southern Peinanshan and Taitung Plain Area}

In this area the Luyeh Fault is interpreted to turn to E-W direction following closely the southern edge of the Peinanshan massif and to join the Lichi Fault in the northern Taitung city. Detail results of velocity field of the near-fault GPS array in this area are shown in Fig. 13. We made two profiles with different orientations to illustrate the near-fault velocity changes: a E-W profile across the southern Peinanshan

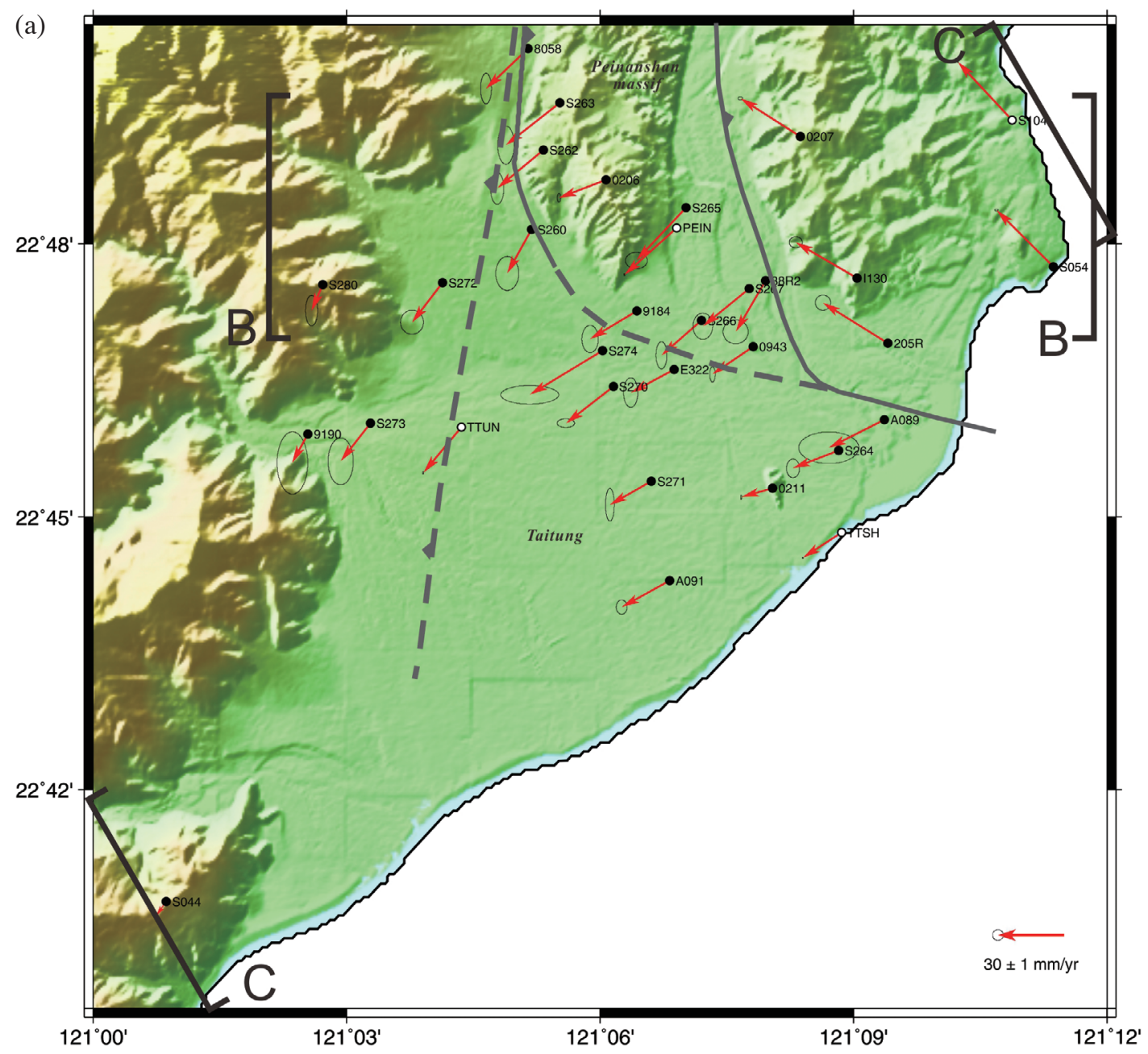

Fig. 13. Detailed velocity field of the near-fault GPS array in the southern Peinanshan Taitung plain area. Station velocities projected to the parallel and normal directions of the strike of the LVF for the two profiles: the E-W trending southern Peinanshan profile in the north and the SW-NE trending Taitung plain profile in the southeast. The locations of the surface traces of the faults are shown as heavy lines. See the main text for the detailed descriptions. 
(b)
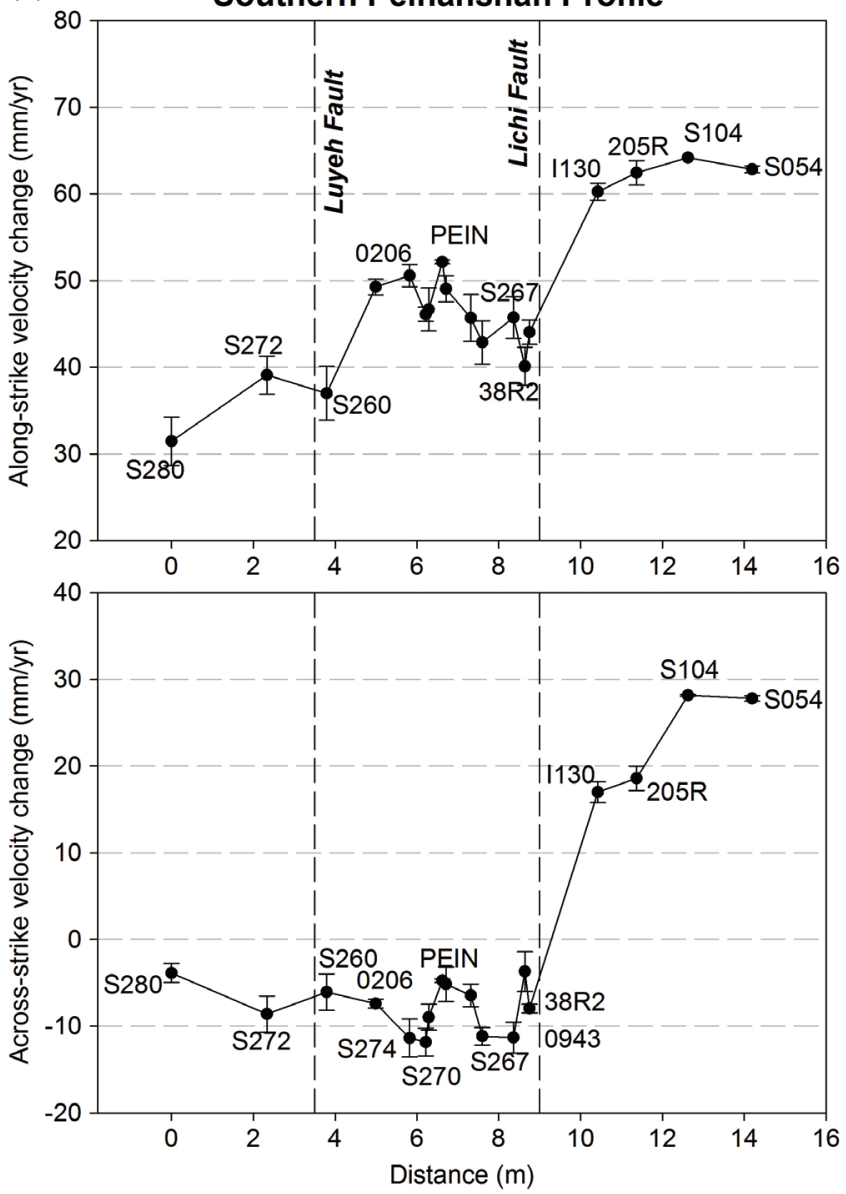

(c) Taitung Profile
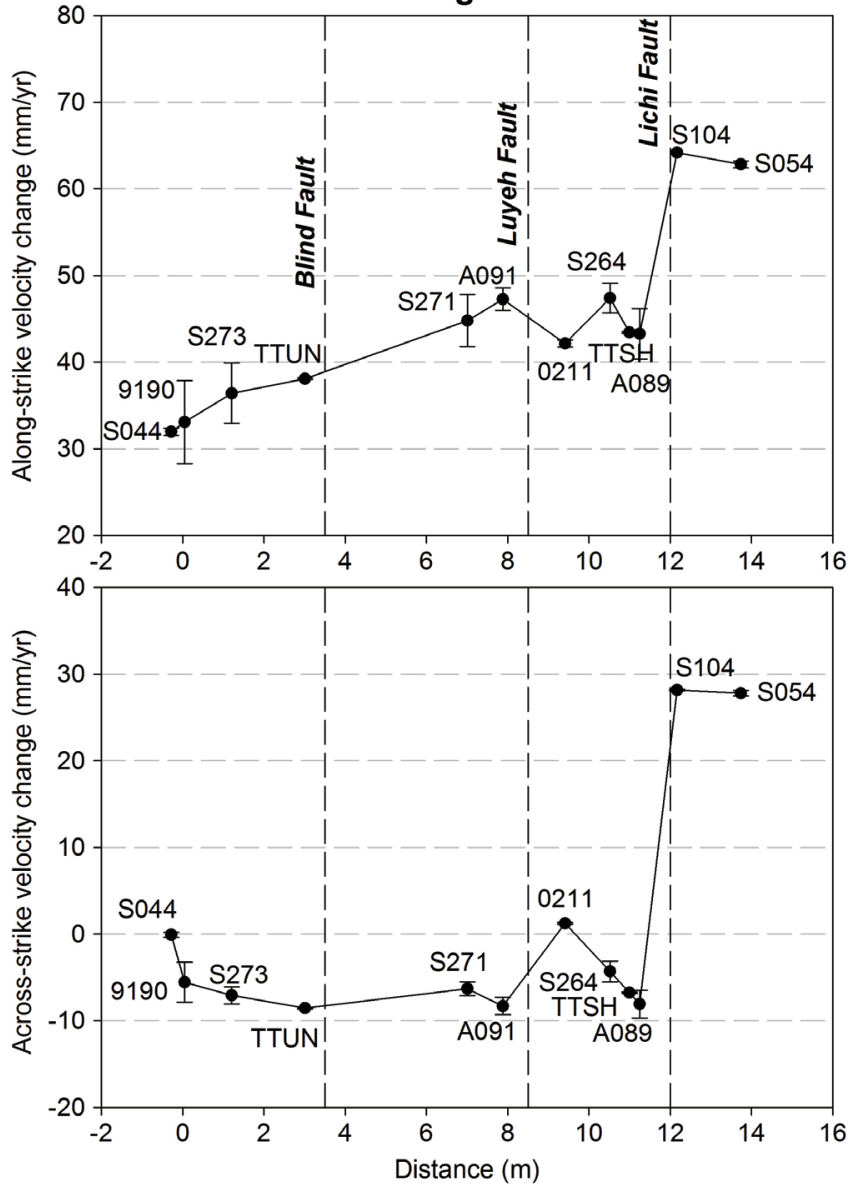

Fig. 13. (Continued)

massif (Fig. 13b) and a SW-NE profile to across perpendicularly to the southern end of the Luyeh-Lichi Fault system in the Taitung plain (Fig. 13c).

The E-W southern Peinanshan profile (Fig. 13b) is consisted of one station in the Central Range (S280), two stations in the western alluvial deposits of the Peinanshan (S272, S260), 4 stations in the Peinanshan tableland (206, S274, S270, 9184), 6 stations in the Peinandachi River bed (PEIN, S265, E322, S266, S267, 38R2), and 4 stations in the Coastal Range (I130, 205R, S104 and S054). We can observe significant shortening (i.e., across-strike component) with much less along-strike shearing around the juxtaposing fault zone of the Central Range and Luyeh Faults. Regarding the Lichi Fault, we find that the surface trace likely follows the eastern side of the Peinandachi River against the Coastal Range where shows significant along-strike velocity change (i.e., a strong left-lateral shearing) and a moderate acrossstrike shortening (Fig. 13b). Further south, the surface trace of the Lichi Fault seemingly turns to E-W direction in the northern Taitung City and we shall discuss the features of velocity changes along the Taitung plain profile.

In the SW-NE trending Taitung plain profile, we find that the largest change of projected velocity occurs across the southern end of the Lichi/Luyeh Fault system, with left-lateral shearing of 24 - $29 \mathrm{~mm} \mathrm{yr}^{-1}$ (fault-parallel component) and extension of 29 - $39 \mathrm{~mm} \mathrm{yr}^{-1}$ (fault-perpendicular component) (Fig. 13c). This left-lateral shearing combining with extension appears to manifest while the two faults join together.

\subsection{Summary of Near-Fault Surface Deformation}

Based on the above analyses, we can make a short summary of near-fault surface deformation as following. First, the Peinanshan tableland seems to play an important role to influence the slip kinematics of the Lichi and Luyeh Faults. Second, the Luyeh River seemingly sits on a structure and the LVF behaves differently on its both sides. The Lichi Fault shows higher rates of oblique shearing/shortening to the north of the Peinanshan tableland (or to the north of the Luyeh River) compared to a moderate rate of pure shearing to oblique shearing/extension against the Peinanshan tableland. Whereas the Luyeh Fault shows in general moderate rates of oblique shearing/shortening from north to south, however, it tends to be more creeping to the north of 
the Peinanshan tableland, compared to be more locked with a deeper locking depth against the Peinanshan tableland. As for the southernmost segment of the Luyeh Fault where it turns to E-W direction, the rates of shearing/shortening become minor without clear surface deformation. Regarding the Central Range Fault, it reveals relatively little interseismic surface deformation across the fault compared to the two branches of the LVF.

\section{DISCUSSIONS}

\subsection{Tectonic Implications from GPS Surface Deforma- tion}

Based on our results of GPS inter-seismic velocity field and the associated strain and fault component kinematics analyses, we are able to clarify a few questions in terms of surface trace of the major active faults and fault kinematics near surface level. Here we focus on discussing three questions: (1) how the Luyeh Fault terminates on both northern and southern ends? (2) Is the Lichi Fault a pure or an oblique strike-slip fault? (3) How the LVF terminates in the southern end on land?

As mentioned above, the near-surface movement on the Luyeh Fault decreases significantly in the northernmost Kaotai tableland, compared to the YongAn Profile (Fig. 11c) and Longtien Profile (Fig. 12b). We thus interpret that the Luyeh Fault diminishes and ends in the northern Kaotai tableland. And there seems no evidence showing development of lateral ramp between the Chihshang Fault and Luyeh Fault. The GPS station velocities in the vicinity between the northern end of the Luyeh Fault and the southern end of the Chihshang Fault are similar and of small values, which show no indication of any possible surface faulting in this area. On the other hand in the southern end of the Luyeh Fault near the northern Taitung plain area, the surface-shortening zone appears to extend southward (Figs. 10 and 13). However, it turns dramatically about $90^{\circ}$ to follow approximately the southern edge of the Peinanshan tableland in a WNW-ESE direction. Although the across-fault shortening decreases and become subtle (Fig. 13b), we tend to interpret that the Luyeh Fault possibly joins the Lichi Fault somewhere in the northern Taitung plain, according the locations and orientations of the two faults.

Concerning the fault kinematics of the Lichi Fault, our results indicate that there exists significant difference on slip kinematics between its northern and southern parts, separated approximately by the Luyeh River. Although the surface strain on both segments share the same orientations of WNW compression or shortening, the northern part of the fault exhibits an oblique thrusting/shortening with significant left-lateral shearing and the southern part shows a dominant left-lateral shearing with minor extension. Geological explanations for this change could be two-fold. First it seems to be related to the existence of the Peinanshan tableland to its footwall of the Lichi Fault and second it probably also is due to the termination of the volcanic arc in the Coastal Range to its hanging wall as a backstop. The lack of strong shortening in the southern part of the Lichi Fault corresponds to the surface geology of the southernmost Coastal Range, where no existence of mechanically stronger volcanic arc but instead occupation of the Lichi melange. However, further investigation is needed to verify this speculation.

The LVF system, after the Luyeh Fault joining the Lichi Fault in the Taitung plain to become one single fault, seemingly orientates in an E-W (or WNW-ESE) direction toward the offshore area. Recent study on seismicity and associated focal mechanisms (O'hara et al. 2011) revealed a possible major E-W active seismogenic structure developing at this latitude, which extends eastward for about $20 \mathrm{~km}$ until the Lutao island (belonging to Luzon arc system). Lack of shortening due to accretion of arc basement along this E-W presumably left-lateral ramp, the southern end of the Longitudinal Valley, including the southern Peinanshan tableland and the Taitung plain, begins to move laterally toward southwest.

\subsection{Effects of Earthquakes V.S. Long-Term Horizontal Surface Deformation}

The four major earthquakes generated large co- and post-seismic displacements, which also caused perturbations of the fault slip kinematics, and in positive or negative sense. We selected 6 longer-occupied stations of CORS in Taitung area to demonstrate the velocity changes after the earthquakes and their effects on long-term surface deformation: S105 and TMAM in the Central Range (Fig. 2), LONT and TTUN in the Longtien tableland and Taitung alluvial (Fig. 3) and ERPN and S104 in the Coastal Range (Fig. 4). In Figs. 2 - 4, the numbers within the parenthesis on the upper right corner express the relative velocity from the entire period without any correction, compared with the velocity above calibrated by Eq. (1). First we discuss the stations in the Central Range (Fig. 2). S105 shows that the perturbations of the Chi-Chi earthquake appeared a temporary effect (Fig. 2a). As a result, the long-term velocity at the station S105 is similar to the inter-seismic velocity. As for the other example in Central Range TMAM, there was no significant velocity change from earthquakes. Thus our derived interseismic horizontal velocity is quite similar to the long-term one. Based on the two above CORS stations, we find that the long-term horizontal velocity is quite similar to the interseismic velocity in the eastern edge of the Central Range. However, it is worth noting that the earthquakes show more significant effects on changing the long-term velocity in the vertical component, although which is not the focus in this paper. It appears that the 2003 Chengkung earthquake and possibly also the 2006 Peinan earthquake produced permanent 
co- and post-seismic displacements on top of the inter-seismic velocity. On the other hand, the earthquake effects behaved differently on the contribution to the long-term vertical deformation at the two stations. The earthquake effect increases the inter-seismic vertical velocity at the S105 (i.e., in a positive sense) but decreases the inter-seismic velocity at TMAM (i.e., in a negative way). Geologically, it implies that whether the stations in eastern Central Range moving slightly upward or slightly downward during the inter-seismic periods, the effects of nearby earthquakes, such as the Chengkung earthquake or the Peinan earthquake, produced a permanent subsidence in the eastern Central Range.

Second, we discuss two stations located in the Longitudinal Valley: LONT on the Longtien tableland and TTUN in the Taitung alluvial plain (Fig. 3). We find that the long-term horizontal velocities are similar to the inter-seismic velocities for both two stations. By contrast, we find that the vertical velocities show more significant differences between the long-term and inter-seismic velocities than those of horizontal ones. However, the earthquake effects behaved differently at the two stations: in a positive way at LONT station but in a negative way at TTUN station. That means, the earthquake effects increased the vertical velocity at LONT (from 5.7 to $8.3 \mathrm{~mm} \mathrm{yr}^{-1}$, i.e., uplift in a more rapid rate) but deceased the vertical velocity at TTUN (form -12.6 to $-8.3 \mathrm{~mm} \mathrm{yr}^{-1}$, i.e., subside in a less rapid rate). Geologically, it also means that the nearby major earthquakes generally produced upward co- and post-seismic permanent movement in the Longitudinal Valley while the stations might move upward or downward during the inter-seismic period.

Third, we discuss two stations in the Coastal Range, EPRN close to the LVF and S104 a little farer away from the LVF (Fig. 4). It appears that the earthquake effects substantially increased the long-term velocities in both horizontal and vertical components. Obviously, this should represent the deformation behaviors of the hanging-wall block of the reverse fault. The three major earthquakes occurred in the vicinity of the LVF released significant amounts of strain, which have been accumulated during the inter-seismic period. It is also worth noting that the earthquakes made a great deal of contributions to the long-term velocities particularly in the vertical component, for instance, 70 and $89 \%$ for EPRN and S104, respectively. On the other hand, only a small portion of the earthquake effects occurred in the longterm horizontal velocities, for instance, 3 and $13 \%$ at EPRN for the north and east components, respectively.

In summary, there were limited, not major contributions from earthquake effects to the long-term horizontal velocity during the time span concerned in this paper in the whole study area. We thus conclude that the inter-seismic horizontal velocities represent at least $90 \%$ or more the long-term horizontal velocities. By contrast, the vertical deformation seemingly was accommodated substantially by the co- and post-seismic deformation of the major earth- quakes in the nearby area, especially for the stations in the Coastal Range.

\section{CONCLUSIONS}

A dense GPS network was deployed around the vicinity of the southernmost Longitudinal Valley in southeastern Taiwan. We estimated the ITRF2005 inter-seismic horizontal velocity field, based on the observations of 86 campaigned GPS stations and 10 continuous GPS stations during 1992 - 2010. Combining with the subsequent strain analysis and projected velocity profiles, we are able to better characterize the surface deformation in particular the slip kinematics of the LVF system and to draw the following conclusions:

(1) We obtained a new inter-seismic horizontal velocity field showing that it is of good quality with small uncertainties.

(2) The surface deformation is mainly accommodated by faulting of the two branches of LVF, i.e., the Luyeh Fault and the Lichi Fault. We find that the E-W trending Luyeh River sits on a location acting as a boundary and that the two above faults behaves differently on the two sides of the Luyeh River. The existence of the Peinanshan tableland to the south of the Luyeh River probably gives a geological explanation for the different slip behaviors in this area.

(3) As for the Lichi Fault, it reveals an oblique left-lateral shearing/thrusting with a strong WNW-ESE shortening to the north of the Luyeh River and a pure shearing to transtension with NNE-SSW extension to the south of the Luyeh River. The middle part of the Lichi Fault appears to cut into Peinanshan tableland instead following the eastern bank of the Peinandachi River. The southern end of the Lichi Fault on land seems to turn significantly to a nearly E-W direction toward the offshore area.

(4) Concerning the Luyeh Fault, it shows a creeping behavior to the north of the Luyeh River with a dominant NW shortening and a partially near-surface locked slip kinematics to the south. The slip of the northernmost Luyeh Fault diminishes and ends in the northern Kaotai tableland. On the southern part, the surface trace of the fault seems to follow the southern edge of the Peinanshan tableland and to turn to E-W direction and presumably join the Lichi Fault in the northern Taitung alluvial plain.

(5) Regarding the Central Range Fault, whose surface trace projection would be close to the Luyeh Fault, our GPS data could not provide enough resolution to better locate its surface trace neither to characterize its inter-seismic slip behavior. This is also due to a relatively slow slip rate and a locked behavior of the Central Range Fault in this area.

(6) The nearby major earthquakes occurred in the observation period showed only a small portion of contributions on the long-term horizontal velocity in the Coastal 
Range and very little in the areas of the Longitudinal Valley and the eastern Central Range. By contrast, a more important co-seismic contribution on long-term velocity for the vertical component, in particular for the Coastal Range.

Acknowledgements The authors would like to express their sincere thanks to several colleagues and assistants who have devoted their efforts to the geodetic surveys for this study. The International GPS Service (IGS) has provided the precise ephemerides for data processing. This research was supported by the Taiwan Earthquake Research Center (TEC) funded through the National Science Council with the grant number NSC 98-2119-M-001-031, NSC 100-2116M-001-004, and NSC 101-2116-M-001-005. The paper is a contribution of the Institute of Earth Sciences, Academia Sinica, IESAS1821, and the TEC, 00093.

\section{REFERENCES}

Altamimi, Z., X. Collilieux, J. Legrand, B. Garayt, and C. Boucher, 2007: ITRF2005: A new release of the International Terrestrial Reference Frame based on time series of station positions and Earth Orientation Parameters. J. Geophys. Res., 112, B09401, doi: 10.1029/2007JB004949. [Link]

Angelier, J., H.-T. Chu, and J.-C. Lee, 1997: Shear concentration in a collision zone: Kinematics of the Chihshang Fault as revealed by outcrop-scale quantification of active faulting, Longitudinal Valley, eastern Taiwan. Tectonophysics, 274, 117-143, doi: 10.1016/S00401951(96)00301-0. [Link]

Chen, H. Y., S. B. Yu, L. C. Kuo, and C. C. Liu, 2006: Coseismic and postseismic surface displacements of the 10 December $2003\left(M_{w} 6.5\right)$ Chengkung, eastern Taiwan, earthquake. Earth Planets Space, 58, 5-21.

Chen, H. Y., Y. J. Hsu, J. C. Lee, S. B. Yu, L. C. Kuo, Y. L. Jiang, C. C. Liu, and C. S. Tsai, 2009: Coseismic displacements and slip distribution from GPS and leveling observations for the 2006 Peinan earthquake $\left(M_{w}\right.$ 6.1) in southeastern Taiwan. Earth Planets Space, 61, 299-318.

Chen, H. Y., J. C. Lee, H. Tung, S. B. Yu, Y. J. Hsu, and H. Lee, 2012: Determination of vertical velocity field of southernmost Longitudinal Valley in eastern Taiwan: A joint analysis of leveling and GPS measurements. Terr. Atmos. Ocean. Sci., 23, 355-376, doi: 10.3319/ TAO.2012.02.29.01(TT). [Link]

Dach, R., U. Hugentobler, P. Fridez, and M. Meindl, 2007: Bernese GPS Software Version 5.0, Astronomical Institute, University of Bern, 612pp.

Frank, F. C., 1966: Deduction of earth strains from survey data. Bull. Seismol. Soc. Am., 56, 35-42.

Hu, J. C., J Angelier, C. Homberg, J. C. Lee, and H. T. Chu
2001: Three-dimensional modeling of the behavior of the oblique convergent boundary of southeast Taiwan: Friction and strain partitioning. Tectonophysics, 333, 261-276, doi: 10.1016/S0040-1951(00)00278-X. [Link]

Lee, J. C. and J. Angelier, 1993: Localisation des déformations actives et traitement des données géodésiques: L'exemple de la Faille de la Vallée Longitudinale, Taïwan. Bull. Soc. géol. Fr., 4, 533-540.

Lee, J. C., J. Angelier, H. T. Chu, S. B. Yu, and J. C. Hu, 1998: Plate-boundary strain partitioning along the sinistral collision suture of the Philippine and Eurasian plates: Analysis of geodetic data and geological observation in southeastern Taiwan. Tectonics, 17, 859-871, doi: 10.1029/98TC02205. [Link]

Lee, J. C., H. T. Chu, J. Angelier, J. C. Hu, H. Y. Chen, and S. B. Yu, 2006: Quantitative analysis of surface coseismic faulting and postseismic creep accompanying the 2003, $\mathrm{M}_{\mathrm{w}}=6.5$, Chengkung earthquake in eastern Taiwan. J. Geophys. Res., 111, B02405, doi: 10.1029/2005JB003612. [Link]

Mozziconacci, L., B. Delouis, B. S. Huang, J. C. Lee, and N. Béthoux, 2013: Determining fault geometry from the distribution of coseismic fault slip related to the 2006 Taitung earthquake, Eastern Taiwan, Bull. Seismol. Soc. Am., 103, 394-411, doi: 10.1785/0120110232. [Link]

Nikolaidis, R., 2002: Observation of geodetic and seismic deformation with the Global Positioning System. Ph.D. Thesis, Univ . of Calif. San Diego, 249pp.

O'hara, D, J. C. Lewis, and R. Rau, 2011: Slip Partitioning Offshore Southeast Taiwan and Southward Propagation of the Longitudinal Valley Fault: Evidence from Preferred Nodal Plane Slip Vectors. American Geophysical Union, Fall Meeting 2011.

Prescott, W. H., 1976: An extension of Frank's method for obtaining crustal shear strains from survey data. Bull. Seismol. Soc. Am., 66, 1847-1853.

Prescott, W. H., J. C. Savage, and W. T. Kinoshita, 1979: Strain accumulation rates in the western United States between 1970 and 1978. J. Geophys. Res., 84, 54235435, doi: 10.1029/JB084iB10p05423. [Link]

Saastamoinen, J., 1973: Contributions to the theory of atmospheric refraction. Bull. geodesique, 107, 13-34.

Shen, Z. K., D. D. Jackson, and B. X. Ge, 1996: Crustal deformation across and beyond the Los Angeles basin from geodetic measurements. J. Geophys. Res., 101, 27957-27980, doi: 10.1029/96JB02544. [Link]

Shyu, J. B. H., K. Sieh, R. Y. Chuang, Y. Wang, L. H. Chung, Y. G. Chen, and the Caltech Ge122 Group, 2002: Deformations of River Terraces near the Luyeh River, Eastern Taiwan, and Their Tectonic Implications. 2002 Annual Meeting of the Geological Society of China, Taipei, 40-43. 
Shyu, J. B. H., K. Sieh, Y. G. Chen, and C. S. Liu, 2005: Neotectonic architecture of Taiwan and its implications for future large earthquakes. J. Geophys. Res., 110, B08402, doi: 10.1029/2004JB003251. [Link]

Shyu, J. B. H., K. Sieh, Y. G. Chen, R. Y. Chuang, Y. Wang, and L. H. Chung, 2008: Geomorphology of the southernmost Longitudinal Valley fault: Implications for evolution of the active suture of eastern Taiwan. Tectonics, 27, TC1019, doi: 10.1029/2006TC002060. [Link]

Wu, Y.M., Y.G.Chen, C.H.Chang,L.H.Chung, T.L Teng, F. T. Wu, and C. F. Wu, 2006: Seismogenic structure in a tectonic suture zone: With new constraints from 2006 Mw6.1 Taitung earthquake. Geophys. Res. Lett., 33, L22305, doi: 10.1029/2006GL027572. [Link]

Yu, S. B. and L. C. Kuo, 2001: Present-day crustal motion along the Longitudinal Valley Fault, eastern Taiwan. Tectonophysics, 333, 199-217, doi: 10.1016/S0040-
1951(00)00275-4. [Link]

Yu, S. B., D. D. Jackson, G. K. Yu, and C. C. Liu, 1990: Dislocation model for crustal deformation in the Longitudinal Valley area, Eastern Taiwan. Tectonophysics, 183, 97-109, doi: 10.1016/0040-1951(90)90190-J. [Link]

Yu, S. B., G. K. Yu, L. C. Kuo, and C. Lee, 1992: Crustal deformation in the southern Longitudinal Valley area, eastern Taiwan. J. Geol. Soc. China, 35, 219-230.

Yu, S. B., H. Y. Chen, and L. C. Kuo, 1997: Velocity field of GPS stations in the Taiwan area. Tectonophysics, 274, 41-59, doi: 10.1016/S0040-1951(96)00297-1. [Link]

Yu, S. B., L. C. Kuo, Y. J. Hsu, H. H. Su, C. C. Liu, C. S. Hou, J. F. Lee, T. C. Lai, C. C. Liu, C. L. Liu, T. F. Tseng, C. S. Tsai, and T. C. Shin, 2001: Preseismic deformation and coseismic displacements associated with the 1999 Chi-Chi, Taiwan, earthquake. Bull. Seismol. Soc. Am., 91, 995-1012. 